\title{
Review Article \\ Role of Mitochondria-Associated Endoplasmic Reticulum Membrane in Inflammation-Mediated Metabolic Diseases
}

\author{
Themis Thoudam, ${ }^{1,2}$ Jae-Han Jeon, ${ }^{3,4}$ Chae-Myeong Ha, ${ }^{1}$ and In-Kyu Lee ${ }^{1,2,3,4}$ \\ ${ }^{1}$ Department of Biomedical Science, Graduate School, Kyungpook National University, Daegu, Republic of Korea \\ ${ }^{2}$ BK21 Plus KNU Biomedical Convergence Program, Kyungpook National University, Daegu, Republic of Korea \\ ${ }^{3}$ Leading-edge Research Center for Drug Discovery and Development for Diabetes and Metabolic Disease, \\ Kyungpook National University, Daegu, Republic of Korea \\ ${ }^{4}$ Department of Internal Medicine, School of Medicine, Kyungpook National University, Daegu, Republic of Korea
}

Correspondence should be addressed to In-Kyu Lee; leei@knu.ac.kr

Received 22 September 2016; Accepted 17 November 2016

Academic Editor: Helen C. Steel

\begin{abstract}
Copyright (C) 2016 Themis Thoudam et al. This is an open access article distributed under the Creative Commons Attribution License, which permits unrestricted use, distribution, and reproduction in any medium, provided the original work is properly cited.

Inflammation is considered to be one of the most critical factors involved in the development of complex metabolic diseases such as type 2 diabetes, cancer, and cardiovascular disease. A few decades ago, the discovery of mitochondria-associated endoplasmic reticulum (ER) membrane (MAM) was followed by the identification of its roles in regulating cellular homeostatic processes, ranging from cellular bioenergetics to apoptosis. MAM provides an excellent platform for numerous signaling pathways; among them, inflammatory signaling pathways associated with MAM play a critical role in cellular defense during pathogenic infections and metabolic disorders. However, induction of MAM causes deleterious effects by amplifying mitochondrial reactive oxygen species generation through increased calcium transfer from the ER to mitochondria, thereby causing mitochondrial damage and release of mitochondrial components into the cytosol as damage-associated molecular patterns (DAMPs). These mitochondrial DAMPs rapidly activate MAM-resident inflammasome components and other inflammatory factors, which promote inflammasome complex formation and release of proinflammatory cytokines in pathological conditions. Long-term stimulation of the inflammasome instigates chronic inflammation, leading to the pathogenesis of metabolic diseases. In this review, we summarize the current understanding of MAM and its association with inflammation-mediated metabolic diseases.
\end{abstract}

\section{Introduction}

Overnutrition leads to metabolic and cellular derangement, which contributes to chronic low-grade inflammation, termed "metainflammation" [1]. Inflammation plays a crucial role in the development of metabolic disorders, which are implicated in the progression of many diseases, including diabetes, cardiovascular disease, and cancer [2]. Drastic changes in cellular metabolism resulting from excessive nutrient intake negatively affect the function of the endoplasmic reticulum (ER) and mitochondria [3-5]. Mitochondria and the ER have their own distinct roles in regulating cellular homeostasis, but these organelles also physically interact, exchanging calcium ions, lipids, and other metabolites to maintain cellular bioenergetics and integrity [6]. The contact region between the ER and mitochondria is known as mitochondria-associated ER membrane (MAM). Recently, intense study of the ER and mitochondrial dynamics has revealed a number of mechanisms involved in the development of inflammation and insulin resistance $[6,7]$. The interaction between the ER and mitochondria is an important cellular process, which occurs rapidly to maintain normal cellular function $[8,9]$. However, abnormal induction of this ERmitochondrial association has been observed in various cell types and tissues under pathological conditions [6, 10-13].

MAM was first identified by J. E. Vance and D. E. Vance a few decades ago, when they described this interface as a major site for the synthesis and transfer of phospholipids [14]. In addition, calcium transfer from the ER to mitochondria via MAM regulates cellular bioenergetics 
by activating calcium-sensitive dehydrogenase, phosphatase, and adenosine triphosphate (ATP) synthase to drive mitochondrial respiration and ATP synthesis [15-18]. Calcium overloading in mitochondria and calcium depletion in the ER due to prolonged induction of MAM lead to mitochondrial and ER dysfunction, thereby resulting in activation of inflammatory and cell death signaling pathways [13, 19-21]. MAM provides a platform for various proteins that control numerous cellular pathways. Of these, inflammasome components and other inflammatory factors play a critical role in initiating inflammatory responses at the MAM interface [7, 22].

In this review, we describe the role of MAM in initiating inflammation and its role in the development of inflammatory diseases.

\section{Cellular Organelle-Mediated Inflammation}

2.1. ER Stress-Associated Inflammation. ER is a cellular organelle that is specialized for protein synthesis, protein folding, and membrane lipid synthesis [38]. The ER lumen can also store a large amount of calcium, which is utilized by ER chaperones for protein folding and to maintain cellular calcium homeostasis $[39,40]$. Under conditions of metabolic stress, such as hypoglycemia, hyperglycemia, or elevated fatty acid levels, ER stress is activated in many tissues [41, 42]. Recent reports show that metabolic diseases such as diabetes, obesity, atherosclerosis, and cancer are linked with aberrant ER stress and inflammation [42]. There are three major independent pathways that control ER stress, namely, the pancreatic ER kinase (PERK), inositol-requiring enzyme 1 (IRE-1), and activating transcription factor 6 (ATF6) pathways, which collectively comprise the unfolded protein response (UPR). All these UPR pathways are responsible for inducing the transcription of genes encoding proinflammatory cytokines $[43,44]$.

The IRE-1 alpha branch is a well-established UPR pathway. Under normal conditions, IRE-1 is bound to the ER chaperone protein glucose-regulated protein 78 (GRP78), but, under conditions of stress, IRE-1 is liberated from GRP78 and undergoes oligomerization, and its ribonuclease domain becomes activated by autophosphorylation. Activated IRE1 catalyzes the splicing of X-box-binding protein 1 (XBP1) mRNA [45] and promotes XBP-1-mediated induction of tumor necrosis factor alpha (TNF- $\alpha$ ) and interferon beta $($ IFN- $\beta$ ) gene expression [46]. In addition, IRE-1 promotes interleukin- 1 beta (IL-1 $\beta$ ) gene expression, via activation of glycogen synthase kinase 3 beta (GSK-3 $\beta$ ), but the mechanism of this effect is less clear [47].

ER stress also results in PERK-dependent activation of the Janus kinase 1/signal transducer and activator of transcription (JAK-1/STAT-3) signaling pathway, which induces expression of the inflammatory cytokine interleukin-6 (IL-6) and that of several chemokines, including C-C motif ligand 2 (CCL2), CC motif ligand 11 (CCL11), and C-C motif ligand 20 (CCL20), in neuronal cells, which drive neuroinflammation [48]. Moreover, CCAAT/enhancer-binding protein homologous protein (CHOP), downstream of PERK, promotes expression of interleukin-23 (IL-23), probably by binding to a specific recognition sequence in its promoter region, which has been identified in dendritic cells [42, 49]. IL-23 is a key mediator of inflammation, because it stabilizes T-helper 17 cells [50].

Lastly, ATF6 is an ER protein that is cleaved into its active form in the Golgi complex during ER stress, which is followed by its translocation into the nucleus, where it functions as a transcription factor to induce acute phase response (APR) genes. The APR commences during the early phases of the innate immune response, involving increased expression of proinflammatory factors, including IL-1, IL-6, and TNF- $\alpha$. ER stress-induced ATF6 expression enhances nuclear factorkappa $B(N F-\kappa B)$ signaling, which in turn inhibits the antiinflammatory protein kinase $\mathrm{B}(\mathrm{PKB} / \mathrm{AKT})$ signaling pathway, thereby enhancing the inflammatory immune response in a mouse model of liver ischemia-reperfusion (IR) injury [51]. An overview of the ER stress-associated inflammatory signaling pathways and their downstream products is shown in Figure 1.

2.2. Mitochondrial Stress-Associated Inflammation. Mitochondria represent cellular power plants, synthesizing ATP through oxidative phosphorylation. They are composed of outer and inner membranes, delineating the intermembrane space, and matrix. They are dynamic cellular organelles that regulate calcium signaling, apoptosis, metabolism, and inflammatory responses [52]. Moreover, they are the primary source of reactive oxygen species (ROS), which are derived from the respiratory chain and drive proinflammatory signaling, NF- $\kappa \mathrm{B}$ expression, and cytokine production [53-55]. Mitochondria are also an important site for NACHT, LRR, and PYD domain-containing protein 3 (NLRP3) inflammasome activation [7]. NLRP3 detects damaged mitochondria and initiates inflammatory responses [56]. As a consequence of NLRP3 inflammasome formation, activated caspase-1 promotes release of proinflammatory cytokines, including IL- $1 \beta$ and IL-18 [57]. In response to viral infection, accumulated and aggregated mitochondrial antiviral-signaling proteins (MAVS) on the mitochondrial outer membrane (OMM) activate interferon regulatory factor 3 (IRF3) and NF- $\kappa$ B [58]. The specific mechanism of this effect will be discussed later in this review.

Mitochondrial dysfunction plays a major role in type 2 diabetes (T2D) [59]. Systemic dysfunction of mitochondria leads to inflammation in pancreatic $\beta$-cells and impaired regulation of blood glucose [57]. This relationship between inflammation and pancreatic cell dysfunction was demonstrated by the use of an IL-1 receptor antagonist to ameliorate hyperglycemia in T2D [60]. Mitochondrial DNA (mtDNA) mutation resulting from oxidative stress is also an etiological factor in the development of rheumatoid arthritis (RA). mtDNA mutation is associated with the induction of proinflammatory cytokines, such as TNF- $\alpha$, and IFN $\gamma$ [61]. Furthermore, as part of its proinflammatory effect, TNF- $\alpha$ promotes ROS production [61]. Mitochondrial dysfunction increases inflammatory responses in normal human synoviocytes, and these are ameliorated by antioxidants, including mitoTEMPO, N-acetylcysteine, and resveratrol [62]. Mitochondria also have multiple roles in cardiac pathophysiology. 


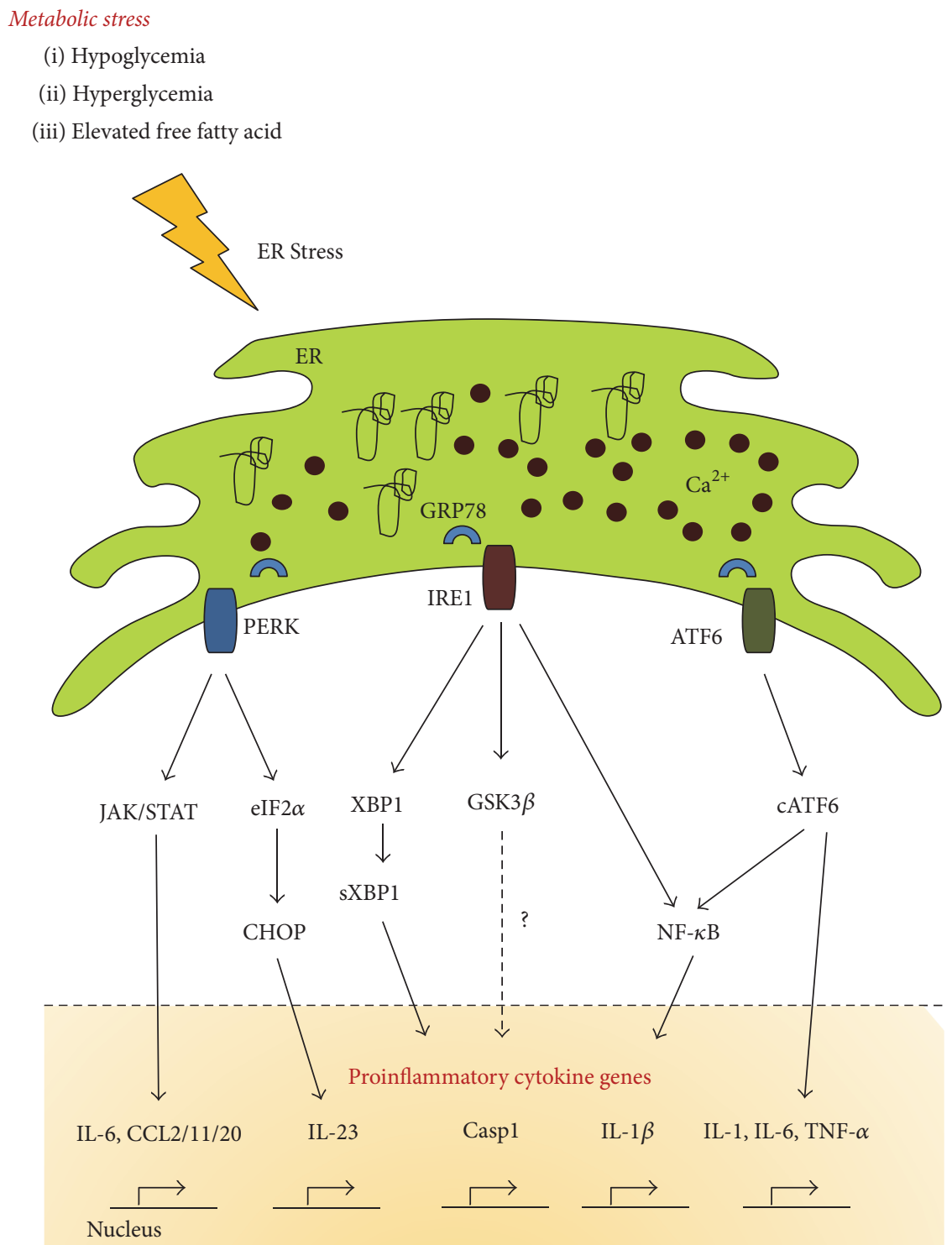

FIgURE 1: Metabolic stress-mediated induction of an inflammatory response via ER stress signaling pathways. Metabolic stressors such as hypoglycemia, hyperglycemia, and elevated free fatty acids induce endoplasmic reticulum (ER) stress pathways that increase production of inflammatory cytokines. PERK activation increases IL-6, IL-23, CCL2, CCL11, and CCL20 gene expression via the JAK/STAT and eIF2 $\alpha-$ $\mathrm{CHOP}$ signaling pathways. IRE1 activation results in increased secretion of a diverse group of proinflammatory cytokines through XBP1, GSK $3 \beta$, and the NF- $\kappa$ B signaling cascade. Lastly, ER stress promotes ATF6 cleavage in the Golgi complex, which triggers proinflammatory cytokine production via the NF- $\kappa$ B pathway. GRP78: glucose-regulated protein 78; PERK: pancreatic ER kinase; IRE1: inositol-requiring enzyme 1; eIF2 $\alpha$ : eukaryotic initiation factor 2 alpha; CHOP: CCAAT-enhancer-binding protein homologous protein; JAK: Janus kinase; STAT: signal transducer and activator of transcription; XBP1: X-box-binding protein 1; sXBP1: spliced X-box-binding protein 1; ATF6: activating transcription factor 6; cATF6: cleaved activating transcription factor 6; GSK $\beta$ : glycogen synthase kinase 3 beta; NF- $\kappa$ B: nuclear factor-kappa B; IL-6: interleukin-6; IL-23: interleukin-23; TNF- $\alpha$ : tumor necrosis factor alpha; IL-1 $\beta$ : interleukin-1 beta; CCL2: chemokine (C-C motif) ligand 2; CCL11: chemokine (C-C motif) ligand 11; CCL20: chemokine (C-C motif) ligand 20; Casp1: caspase-1.

Sterile inflammation (in the absence of microorganisms) in the heart involves mitochondrial dysfunction [63]. For example, damage-associated molecular patterns (DAMPs) generated from mtDNA induce systemic inflammatory responses during pressure overload [64]. Taken together, these findings support the critical role of mitochondrial dysfunction in chronic inflammatory diseases.

\section{Role of Mitochondria-Associated ER Membrane}

3.1. Role of MAM in Lipid Metabolism. MAM is enriched with enzymes involved in phospholipid synthesis $[65,66]$. Phospholipids are synthesized at the ER-mitochondrial interface, because each organelle does not possess all the 
required enzymes to complete the whole process [67]. Phosphatidylethanolamine (PE) and phosphatidylcholine (PC) are among the most abundant phospholipids on the ER membrane. The precursor phosphatidic acid (PA) is converted into phosphatidylserine (PS) by phosphatidylserine synthases 1 and 2 (PSS1 and PSS2) in the ER. PS is then transferred to mitochondria, where phosphatidylserine decarboxylase (PSD) converts it to PE. Lastly, PE is transferred to the ER from mitochondria to synthesize PC using phosphatidylethanolamine methyltransferase 2 (PEMT2) [68]. PC is a preferred component of lipid droplet packaging and lipoproteins [69]. The PC/PE ratio is maintained within a narrow range, and an inappropriate ratio has been identified as a major factor in the progression of steatohepatitis [70]. An increase in the PC/PE ratio was also observed in obese mice, which affected ER calcium-restoring capacity by inhibiting activity of the ER calcium importer sarco/endoplasmic reticulum $\mathrm{Ca}^{2+}$-ATPase (SERCA) [5].

MAM is also actively involved in cholesterol transport into mitochondria and steroidogenesis in steroid-synthesizing cells, for example, mouse Leydig cells and rat adrenal gland. Cholesterol transport within mitochondria and steroidogenic activity is dependent upon the expression level and stability of steroidogenic acute regulatory protein (StAR), which is abundant at the MAM. StAR interacts with another MAM-resident protein, voltage-dependent anion channel 2 (VDAC2), and this interaction was found to be crucial for StAR translocation at the MAM, before it is targeted to mitochondria for its role in steroidogenesis [71].

3.2. Role of MAM in Calcium Homeostasis. Another pivotal role of MAM is in calcium transport. The OMM ion channel voltage-dependent anion channel (VDAC), the chaperone protein glucose-regulated protein 75 (GRP75), and the ER calcium channel inositol 1,4,5-triphosphate receptor (IP3R) form a macromolecular complex to mobilize calcium from the ER to mitochondria. Knocking down of GRP75 disrupts this complex and reduces mitochondrial calcium uptake [72]. In addition, calcium exchange between the ER and mitochondria can occur through another ER calcium channel, ryanodine receptor (RyR), and VDAC $[37,73]$. Apposition of mitochondria and ER via MAM provides a sturdy platform to maintain a strong calcium concentration gradient around the mitochondrial calcium channel VDAC, allowing it to take up calcium more efficiently [74, 75]. Following this, the mitochondrial calcium uniporter (MCU), located in the mitochondrial inner membrane, imports calcium from the mitochondrial intermembrane space to the mitochondrial matrix [76]. At a physiological concentration of matrix calcium, aerobic metabolism and ATP synthesis are stimulated by activation of calcium-sensitive mitochondrial metabolic enzymes [77]. During the extreme rise in matrix calcium that can occur in pathological conditions, enhanced ROS generation occurs, which eventually leads to a collapse in mitochondrial function and apoptosis, via opening of mitochondrial permeability transition pores (mPTPs) $[17,78,79]$. Taken together, it is likely that accumulation of mitochondrial calcium, occurring because of an abnormal induction of MAM, leads to apoptosis via MPTP opening.
3.3. MAM as an Interorganelle Platform for Cellular Signaling Pathways. MAM harbors numerous proteins that play a crucial role in cellular metabolism, growth, and survival. AKT kinase is well known for its role in cell proliferation. Hyperactive AKT signaling pathways are frequently observed in many human cancers [80]. In vitro and in vivo studies have found that AKT inhibits ER calcium channel IP3R activity via direct phosphorylation, thereby limiting calcium release from the ER [81, 82]. ER calcium release via IP3R has been reported to play a key role in initiating intrinsic apoptosis by modulating mitochondrial calcium accumulation [81]. The C-terminal tail of all three isoforms of the inositol 1,4,5-trisphosphate (IP3) receptor, namely, IP3R1, IP3R2, and IP3R3, carries a conserved consensus RXRXX (S/T) substrate motif for AKT kinase [82]. Mutations in the AKT phosphorylation site of IP3R promote ER calcium release mediated by cellular stress and apoptosis. Overexpression of constitutively active AKT dramatically reduces ER calcium release, decreases mitochondrial calcium levels, and prevents apoptosis initiated by various calcium-dependent apoptotic stimuli [83]. These findings shed light on the mechanism that allows cancer cells to escape cell death pathways activated by the hyperactivation of AKT signaling pathways. Interestingly, AKT translocates at the MAM interface, which allows it to regulate IP3R activity and MAM integrity $[19,28]$. Growth hormone-regulated mTOR Complex 2 (mTORC2), which plays a role in cellular proliferation, resides at the ER membrane and MAM, where it induces calcium mobilization from the ER to mitochondria. mTORC2 activates AKT by phosphorylation, thereby inhibiting IP3R3 and suppressing calcium release from the ER to mitochondria. In addition, mTORC2-mediated AKT activation potentiates MAM integrity by phosphorylating phosphofurin acidic cluster sorting protein 2 (PACS2), an ER protein that tethers mitochondria at the MAM interface [19].

Phosphatase and tensin homolog (PTEN) is a tyrosine phosphatase that preferentially dephosphorylates phosphoinositide substrates and negatively regulates insulin action by counteracting the effects of PI3-kinase, which converts phosphatidylinositol $(3,4,5)$-bisphosphate (PIP2) to phosphatidylinositol $(3,4,5)$-trisphosphate (PIP3) [84]. Furthermore, suppression of PTEN protects against insulin resistance in diet-induced obese (DIO) and $o b / o b$ mice models $[85,86]$. PTEN is located in a number of subcellular compartments, including the plasma membrane, cytoplasm, mitochondria, and nucleus [87-89]. Interestingly, PTEN is also enriched in MAM, where it can regulate ER to mitochondrial calcium mobilization [28]. In addition, PTEN reverses the AKTmediated IP3R3 phosphorylation that terminates this calcium flux. The increased calcium influx from the ER to mitochondria mediated by MAM-localized PTEN induces mitochondrial calcium-dependent apoptosis as a tumor suppressing mechanism [28].

GSK- $3 \beta$ is an enzyme that phosphorylates and inactivates glycogen synthase $[90,91]$. It protects cells from death by manipulating the threshold for mPTPs under conditions of cardiac hypertrophy and IR injury [92, 93]. Surprisingly, a recent study revealed that GSK-3 $\beta$ is relocated to MAM, where it regulates IP3R1-mediated calcium release, thereby inducing calcium accumulation in mitochondria 
and $\mathrm{mPTP}$ pore opening. Inhibition of GSK- $3 \beta$ could thus play a critical role in cardioprotection during IR injury [24].

\section{MAM Association with Cellular Stress Pathways Which Triggers Inflammation}

4.1. Hypoxia. Reduction in oxygen availability during hypoxia alters cellular metabolism; oxidative phosphorylation in mitochondria is decreased, and, instead, cellular ATP generation mainly relies on glycolysis [94]. Hypoxia induces synthesis of the transcription factor hypoxia-inducible factor $1 \alpha$ (Hif $1 \alpha)$. Hif $1 \alpha$ promotes glucose catabolism by inducing transcription of several enzymes involved in glycolysis $[95,96]$. Moreover, it suppresses pyruvate metabolism in mitochondria by inducing pyruvate dehydrogenase kinase 1 (PDK1) transcription. Hypoxia and inflammation are very closely related mechanisms in metabolic diseases [97, 98]. Individuals with acute mountain sickness and healthy hikers who are exposed to hypoxia at high altitude have higher levels of circulating proinflammatory cytokines $[99,100]$. Moreover, hypoxia is a major factor causing inflammatory diseases such as atherosclerosis, RA, inflammatory bowel disease, and colorectal cancer [101-103]. In obese subjects, hypoxia is observed in rapidly enlarged adipose tissue depots. Here, inflammation is also observed, evidenced by increased infiltration with macrophages [104]. Enlarged adipose tissue depots secrete inflammatory cytokines such as monocyte chemoattractant protein-1 (MCP-1), IL-6, IL-1, and TNF- $\alpha$, which can initiate inflammatory reactions $[105,106]$. Conversely, the anti-inflammatory adipokine adiponectin, which plays a protective role in diabetes and atherosclerosis [107], was found to be reduced in obese subjects $[108,109]$ and adipocytes exposed to hypoxia [110-113].

Interestingly, FUN14 domain-containing 1 (FUNDC1), a protein present in the mitochondrial membrane, was previously found to mediate hypoxia-induced mitophagy by directly interacting with the autophagosome component microtubule associated protein 1 light chain 3 (LC3) protein in mammalian cells [114]. Recently, it was also found to interact with the ER resident protein calreticulin at the MAM interface and to act as an adaptor for dynamin-related protein 1 (Drp1) recruitment in mitochondria, thereby inducing hypoxia-mediated mitochondrial fission and mitophagy [115]. This report therefore revealed a close relationship between hypoxia and MAM. Further study is required to understand the importance of MAM in mediating inflammatory responses under hypoxic conditions.

\subsection{Mitochondrial Dynamics}

4.2.1. Mitochondrial Fusion. Mitochondria actively undergo fusion and fission processes to maintain their functions. Mitochondrial fusion is considered to be crucial for cellular survival and recovery after stressful conditions [116]. This process is accomplished by the action of mitofusin 1 (Mfn1) and mitofusin 2 (Mfn2), present in the OMM, and optic atrophy 1 (OPA-1), present in the mitochondrial inner membrane. Mitochondria that are unable to regain their function undergo fission to promote mitophagy, or, in the case of severe mitochondrial damage, undergo apoptosis [117]. Mfn1 and Mfn2 are crucial proteins modulating mitochondrial tethering, docking, and fusion [118]. During mitochondrial fusion, Mfn1 helps tethering adjacent mitochondria in a GTP-dependent manner, whereas Mfn2 is tethered with low efficiency. Mfn1 and Mfn2 form homotypic or heterotypic complexes during mitochondrial fusion in the mammalian cell $[119,120]$. In addition, Mfn2 is proposed to be a prominent candidate tethering ER and mitochondria by localizing to the MAM interface. In addition to its localization to the mitochondrial outer membrane, Mfn2 also localizes to the ER membrane. Its localization to the ER membrane allows it to bind to Mfn1 or Mfn2 present on adjacent mitochondria, which promotes the formation of a bridge between the ER and mitochondria. Subsequently, Mfn2 deficiency leads to a reduction in mitochondrial calcium uptake rate [121].

However, several conflicting results questioning the indispensability of Mfn2 as an ER-mitochondria tether have been reported recently [122-124]. One of the reports showed that cells lacking Mfn2 or cells treated with siMfn2 still maintain contact between the ER and mitochondria. This finding challenges numerous other reports describing Mfn2 as a prominent marker for MAM formation [123]. However, we cannot rule out the possibility that other MAM tethers maintain integrity and compensate for the absence of Mfn2. Surprisingly, another independent study showed that Mfn2deficient cells manage to maintain close proximity between the ER and mitochondria; however, these cells are less sensitive to MAM mediated mitochondrial calcium uptake than control cells and do not show disruption in the mitochondrial calcium transport system. This finding supports the notion that Mfn2 is still an essential component [125]. Mitofusins have been reported to be involved in several metabolic diseases [117, 126]. The role of Mfn-1 has been much less explored than that of Mfn-2. A previous study found that cardiomyocyte specific Mfnl knockout (KO) mice exhibit normal left-ventricular function and that mitochondrial respiration is normal in cardiomyocytes isolated from the Mfn$1 \mathrm{KO}$ heart. Surprisingly, Mfn1 KO cardiomyocytes are less sensitive to mitochondrial depolarization and show higher cell viability than wild-type cardiomyocytes after challenge with hydrogen peroxide [127]. Another report showed that Mfn1 overexpression leads to hyper fusion of mitochondria, which negatively affects mitochondrial function and mitochondrial motility in INS-1E rat clonal beta cells [128]. On the other hand, the role of Mfn2 has been extensively studied by numerous groups because it is associated with many metabolic syndromes. Charcot-Marie-Tooth disease type $2 \mathrm{~A}$ has been linked with an Mfn2 mutation [129] that results in the loss of Mfn2 activity [130]. Moreover, Mfn2 expression levels are reduced in skeletal muscle of obese and diabetic humans [131]. In addition, rats fed with HFD for 8 weeks have lower Mfn2 gene expression than control rats, and this lower expression is accompanied by attenuated insulin signaling in the liver. Overexpression of Mfn2 compensates for HFD-mediated disruption of insulin signaling [132]. Liverspecific Mfn2 KO mice have higher levels of mitochondrial 
fragmentation and glucose intolerance and lower responses to insulin in the liver. Deficiency of Mfn2 also negatively affects mitochondria function by reducing mitochondrial respiration and enhancing ROS generation in the mouse liver [133]. Interestingly, an Mfn2 loss-of-function mutant shows impaired glucose, pyruvate, and palmitate oxidation caused by low OXPHOS complex subunits expression, whereas a Mfn2 gain-of-function mutant shows higher mitochondrial metabolism in skeletal muscle cells caused by high OXPHOS complex subunit expression [134]. Cardiomyocytes lacking Mfn2 are more viable against ischemia-reperfusion heart injury by reducing mitochondrial calcium overload and ROS generation and by delaying $\mathrm{MPTP}$ pore opening [135].

4.2.2. Mitochondrial Fission. Mitochondrial fission involves the Drpl protein, which is recruited from the cytosol to the OMM by various adaptors such as mitochondrial fission protein 1 (Fis-1), mitochondrial fission factor (MFF), mitochondrial dynamics protein of $49 \mathrm{kDa}$ (MiD49), and mitochondrial dynamics protein of $51 \mathrm{kDa}$ (MiD51), which are present on the OMM [114]. In this context, MAM plays an important role during the fission process by wrapping the damaged mitochondria with ER membrane, thereby promoting Drp1 translocation to the ER-mitochondria interface, where it can cleave mitochondria efficiently and target damaged mitochondria for mitophagy [136-138]. The connection between inflammation and mitochondrial fission is well documented: the bacterial component lipopolysaccharide (LPS) induces Drp1 translocation from the cytosol to mitochondria and promotes mitochondrial fission, accompanied by increased expression of genes encoding proinflammatory cytokines. By contrast, blocking Drp1 translocation to mitochondria or knocking down the Drp1 gene results in downregulation of proinflammatory cytokine gene expression in LPS-stimulated microglial cells [139].

4.3. Autophagy. Autophagy is an essential cellular mechanism that is required for degrading damaged cellular components and removing them from cells, to protect them from further damage. Extensive research in the field of autophagy has revealed that autophagosome formation originates in the MAM [140].

Autophagy plays an important role during bacterial and viral infections; the specific term for the degradation of foreign pathogens by autophagy is "xenophagy." Studies of genetically and diet-induced obese mouse models demonstrated a suppression of autophagy in liver, adipose tissue, and beta cells [141-143]. Moreover, DIO mice displayed impaired autophagy in macrophages, provoking polarization into the proinflammatory M1 subtype [144]. This suppression of autophagy increased the accumulation of damaged intracellular organelles and amplified the inflammatory response [64, 145-147]. In addition, induction of autophagy in macrophages protected against bacterial infection and suppressed damaging inflammation [148-150]. However, direct evidence of the importance of MAM in linking autophagy and inflammation is still lacking, and therefore this would be an interesting area for future studies.

\section{Inflammatory Signaling at the MAM Interface}

5.1. NLRP3. NLRP3, also known as cryopyrin, is a member of the nucleotide-binding domain and leucine-rich repeatcontaining (NLR) protein family. NLR proteins are involved in the induction of inflammatory responses in response to invading foreign pathogens and intracellular, cellular, or tissue damage. NLR proteins recognize diverse pathogenic molecules, when they become activated and assemble into inflammasome complexes with other inflammasome components. These complexes then promote proinflammatory cytokine secretion as an immunologic response [151]. Unlike other NLR family members, NLRP3 recognizes not only foreign pathogenic particles but also DAMPs released from damaged mitochondria [152].

NLRP3 is expressed in most tissues but predominantly in macrophages. It localizes to the ER membrane in its resting state and relocates to MAM in its activated state, where it detects increased ROS production from damaged mitochondria. It is worth noting that increased ER-mitochondrial association induces calcium accumulation in mitochondria and exacerbates mitochondrial dysfunction and ROS production. Moreover, calcium accumulation is the major factor that causes opening of $\mathrm{mPTP}$ and thereby the release of mitochondrial components that activate the inflammasome via NLRP3. Furthermore, increased NLRP3 inflammasome activation and IL- $1 \beta$ secretion are observed after inhibition of mitophagy/autophagy by 3-methyladenine (3MA) treatment or after knocking down the autophagy regulator beclin 1 and autophagy protein 5 (ATG5) in macrophages, resulting in accumulation of damaged mitochondria and increased ROS generation. Similarly, induction of mitochondrial damage using a series of mitochondrial respiratory chain inhibitors amplifies IL- $1 \beta$ secretion. However, treatment with the antioxidant 4-amino-2,4-pyrrolidinedicarboxylic acid (APDC) blocked NLRP3 inflammasome activation and IL- $1 \beta$ secretion [7].

Small heterodimer partner (SHP) negatively regulates NLRP3 inflammasome activation by inhibiting binding of NLRP3 to apoptosis-associated speck-like protein containing a CARD (ASC) protein. Hence, LPS stimulation in SHPdeficient macrophages leads to accumulation of damaged mitochondria and sustained interaction between NLRP3 and ASC protein in the ER, which is accompanied by increased secretion of IL-1 $\beta$ and IL- 18 . Excessive IL-1 $\beta$ and IL-18 secretion is typically observed in kidney tubular necrosis with peritoneal gout, diabetes, atherosclerosis, and Alzheimer's disease (AD) [153]. In addition, the ER-initiated UPR activates the NLRP3 inflammasome to contribute to ER stress-mediated chronic inflammation, while blockade of NLRP3-induced IL$1 \beta$ release or blockade of the IL- 1 receptor improves glucose homeostasis $[154,155]$.

5.2. ASC. ASC is an important component of the inflammasome [156], and it forms a complex with NLRP3 to recruit caspase- 1 and promote IL- $1 \beta$ maturation and secretion. ASC proteins are predominantly localized to the cytosol, but a small proportion are also found in the ER under unstimulated 
conditions. Stimulation with the microbial toxin nigericin or monosodium urate crystals increased ASC translocation at MAM and also to a lesser extent in mitochondria. Its translocation at MAM was found to be a NLRP3-dependent mechanism. ASC was found to be crucial for IL-1 $\beta$ maturation and secretion, because ASC KO cells significantly reduced IL-1 $\beta$ secretion [7]. Furthermore, ASC knockout mice are protected from high fat diet-induced hepatic insulin resistance, hepatic steatosis, and adipocyte hypertrophy [157, 158]. Proinflammatory cytokines such as IL-1 $\beta$ and IL-18 are considered to be important factors linking inflammation to insulin resistance $[159,160]$. Caspase-1-deficient mice are also protected from diet-induced obesity. IL-1 $\beta$ production and macrophage infiltration in adipose tissue were significantly lower in these mice [157]. In summary, therefore, MAM provides an ideal platform for the activation and assembly of the NLRP3, ASC, and caspase-1 inflammasome complex, which is required for the maturation of the proinflammatory cytokines, IL-1 $\beta$ and IL-18.

5.3. MAVS. MAVS is a protein that has been previously known as virus-induced signaling adaptor (VISA), IPS-1, and cardif. It is localized in peroxisomes and mitochondria and plays a major role during hepatitis $\mathrm{C}$ virus (HCV) infection. $\mathrm{HCV}$ invasion is recognized by retinoic acid-inducible gene1 protein (RIG-I), a pattern recognition receptor (PRR) that activates MAVS to initiate an antiviral response through NF$\kappa \mathrm{B}$ and interferon regulatory factor 1 (IRF-1) signaling pathways [161-163]. Interestingly, MAVS was found to localize at the MAM in human hepatoma cells (HUH7 cells) $[161,164]$. During HCV infection, cytosolic RIG-I detects the dsRNA of $\mathrm{HCV}$, triggering its relocation to the MAM to activate MAVS. As a result, activated MAVS plays a crucial role in the activation of NF- $\kappa \mathrm{B}$ and IFN- $\alpha$ production. However, during chronic $\mathrm{HCV}$ infection, the NS3/4A protease produced by $\mathrm{HCV}$ is translocated to the MAM to specifically cleave MAVS at this location, thereby suppressing the MAVS-mediated proinflammatory response [161]. In addition, MAVS detects viral RNA through its interaction with RIG-I and melanoma differentiation-associated protein 5 (MDA-5), resulting in increased expression of IFN- $\beta$ [165]. Most importantly, MAVS is as important as ASC for inflammasome activation, because MAVS acts as an adaptor for NLRP3, and is required for its optimal function and recruitment to mitochondria, where IL- $1 \beta$ but not IFN- $\beta$ is generated (Figure 3 ). Therefore, MAVS plays a crucial role in inflammasome formation, thereby promoting IL- $1 \beta$ production in response to tissue injury and necrosis [166].

5.4. $\alpha$-Synuclein. The neurodegenerative process that occurs during Parkinson's disease (PD) is caused by inflammation in neuronal cells [167]. Previous reports have identified increased levels of TNF- $\alpha$ and IL- $1 \beta$ in the striatum and in peripheral blood mononuclear cells in patients with idiopathic PD [168-171]. These findings have also been corroborated by many other groups using PD mouse models [172174]. $\alpha$-Synuclein is an abundant protein in brain, which, when mutated, causes toxic gain of function and abnormal aggregation of Lewy bodies, leading to the development of PD [175]. Moreover, this abnormal aggregation activates microglial cells and increases the production of proinflammatory cytokines [167].

Synuclein is predominantly localized in the cytosol [176] and to a lesser extent in mitochondria $[177,178]$, but its presence in MAM suggests its involvement in the development of PD. Interestingly, pathological mutation of $\alpha$-synuclein leads to disruption of ER-mitochondrial interaction and is accompanied by reduced MAM activity. Surprisingly, suppression of MAM in cells carrying mutant $\alpha$-synuclein resulted in increased mitochondrial fragmentation, which was independent of the fission inducer Drpl. Consistent with this, reexpression of wild-type $\alpha$-synuclein in cells carrying the mutant version rescued mitochondria from fragmentation. Taken together, wild-type $\alpha$-synuclein plays a crucial role in maintaining mitochondrial health, but its mutation, which is normally observed in PD, causes mitochondrial fragmentation, which is consistent with the increased number of damaged mitochondria that are present in PD [34]. However, it was reported that $\mathrm{PD}$ patients with a parkin RBR E3 ubiquitin protein ligase (PARK2) mutation showed enhanced MAM formation, an observation that was replicated using PARK2 KO mice [33], and which implicates an alternative mechanism for the development of PD.

5.5. Presenilins. Presenilin protein is well known for its association with $\operatorname{AD}[179,180]$. It is a component of $\gamma$-secretase enzymes, which are responsible for cleaving amyloid precursor protein (APP) into amyloid beta $(A \beta)$. Presenilin mutations lead to increased aggregation and accumulation of $\mathrm{A} \beta$, which is the key pathogenic factor in AD [181, 182]. Two isoenzymes exist, presenilin-1 (PS1) and presenilin-2 (PS2), and both proteins were found to be enriched in MAM fractions from neuronal and nonneuronal cells. Presenilin found in MAM is functional; thus APP cleavage into $\mathrm{A} \beta$ can occur on MAM [183]. Interestingly, MAM formation was found to be upregulated in PS mutant cells and in fibroblasts from both familial and sporadic cases of PD [10]. However, PS2 requires interaction with mitofusin 2 to positively modulate calcium exchange between the ER and mitochondria. In addition, AD-linked PS2 mutants are more effective than wild-type PS2 in tethering the ER and mitochondria [32].

Inflammation is actively involved in the pathogenesis of $\mathrm{AD}$ [184]. $\mathrm{AD}$ that is linked with a PS mutation is characterized by increased levels of MCP-1, IL-6, and IL-8 release, while a PS1 mutation in microglial cells amplified TNF- $\alpha$, IL- $1 \alpha$, IL- $1 \beta$, and IL- 6 gene expression [185]. All these findings highlight the importance of the MAM-localized protein PS in the progression of AD.

\section{Stress Sensors at the MAM Interface}

6.1. PERK. Under normal conditions, PERK is bound to the GRP78 ER chaperone protein, but, during ER stress, GRP78 is released from PERK and activated by autophosphorylation. Its activation suppresses translation by phosphorylating eukaryotic initiation factor 2 alpha $(\operatorname{eIF} 2 \alpha)$ at serine 51 and reduces transcription of I kappa B alpha $(\mathrm{I} \kappa \mathrm{B} \alpha)$, which leads to hyperactivation of $\mathrm{NF}-\kappa \mathrm{B}$ and increased 
inflammatory cytokine production $[186,187]$. PERK is an ER membrane protein that detects increases in mitochondrial ROS and activates the UPR signaling pathway. PERK is found abundantly in MAM, where its role is not confined to the activation of its canonical pathway that is eIF $2 \alpha$-ATF4mediated induction of the proapoptotic factor CHOP but also encompasses ROS detection and ER and mitochondrial tethering (Figure 2) [188]. PERK-mediated CHOP induction increases the transcription of BAX protein, which inhibits the antiapoptotic OMM protein B-cell lymphoma 2 (Bcl-2) and participates in MPTP pore opening.

6.2. PML. Promyelocytic leukemia protein (PML) is a tumor suppressor protein that mediates multiple apoptotic responses [189]. PML localization in MAM promotes calcium-dependent apoptotic cell death. Under normal conditions, PML forms a protein complex with IP3R3, AKT, and protein phosphatase 2 (PP2a), which regulates cell fate by increasing mitochondrial calcium and apoptosis, but, in cancer cells, the expression of PML is generally low, making them resistant to cell death [189].

6.3. p53. Tumor protein p53 (p53) activity regulates cell cycle arrest and apoptosis in malfunctioning cells. It is a transcription factor that regulates expression of DNA repair proteins and initiates the production of apoptotic signals when it detects damaged and irreparable DNA [190, 191]. p53 has been found in many subcellular compartments, including the nucleus, cytosol, and mitochondria, and its proapoptotic effects when localized to mitochondria are transcriptionindependent [192]. However, p53 accumulation in the ER and MAM was recently reported in cancer cells treated with an anticancer drug, which promoted mitochondrial calcium accumulation, followed by mitochondrial fragmentation and apoptosis [26].

6.4. p66Shc. The MAM-resident protein $66 \mathrm{kDa}$ isoform of the growth factor adapter Shc (p66Shc) regulates mammalian cell life span by increasing ROS generation (Figure 2). Previously, it was found to reside within mitochondria, by virtue of a mitochondrial targeting sequence [193], but its exact location within mitochondria is still controversial [194, 195]. Its activity is highly increased in aged mice due to increased phosphorylation by protein kinase $\mathrm{C}$ beta $(\mathrm{PKC} \beta)$ in the MAM fraction, which results in increased ROS generation and cellular senescence [27].

\section{Role of MAM in Mitochondrial DAMP Generation}

The evolutionary origin of mitochondria from a bacterial endosymbiont suggests that components released from damaged mitochondria may act as a trigger for mechanisms used to detect damaged cells and drive immunologic responses [196].

Two common factors that initiate inflammation are pathogen-associated molecular patterns (PAMPs) and DAMPs [196]. Components of microorganisms such as LPS, endotoxins, and flagellin, found on bacterial cell membranes, are considered to be the prototypical class of PAMPs. PAMPs are recognized by toll-like receptors (TLRs) and PRRs present on the host cell membrane [197]. By contrast, DAMPs are generated within host cells in response to cellular damage caused by extensive cellular stress, either in the absence or in the presence of pathogenic infection [198]. DAMP-triggered inflammation in the absence of any foreign pathogen is defined as sterile inflammation, and it has been widely studied due to its critical role in the development of inflammatory diseases [199, 200]. Mitochondria-derived DAMPs such as ATP, ROS, mtDNA, cytochrome C, cardiolipin, succinate, and $\mathrm{N}$-formyl peptide play a pivotal role in the activation of NLRP3-mediated inflammatory responses [201].

Another recent study revealed that Brucella abortus strain RB51 infection in mouse bone marrow-derived macrophages (BMDMs) leads to induction of mitochondrial DAMPs. RB51 infection induced the ER stress marker IRE-1, but not ATF6 or PERK. IRE-1 activation promoted thioredoxininteracting protein (TXNIP) translocation to mitochondria [202]. TXNIP was previously shown to have a different subcellular localization, but its translocation to mitochondria inactivates thioredoxins/trx proteins, which act as antioxidants by facilitating the reduction of other proteins by cysteine thiol-disulfide exchange, and increases ROS production [203, 204]. Increased formation of mitochondrial ROS induces NLRP3 translocation to the OMM and presumably to MAM, where caspase-2 translocation to the OMM is promoted. Here, caspase- 2 cleaves and thereby activates $\mathrm{BH} 3$ interacting-domain death agonist (BID), which facilitates BAX/BAK-mediated mitochondrial DAMP release (Figure 2) [202]. However, it is not clear that activation of IRE-1 triggered by RB51 infection or treatment with LPS requires MAM formation. IRE-1 protein has previously been detected in MAM, where it was found to act as a ROS sensor. Exposure to high concentrations of ROS activates and stabilizes IRE1 through interaction with the chaperone protein sigma-1 receptor (Sig-1R) on MAM. Activation of IRE-1 promotes XBP-1 activation as a protective response against ER stress [205]. However, the importance of MAM for IRE-1-mediated inflammasome activation requires further assessment.

The mitochondrial matrix protein cyclophilin $\mathrm{D}(\mathrm{CypD})$, which modulates opening of $\mathrm{mPTP}$, was found to reside in MAM and to interact with the VDAC1, GRP75, and IP3R1 complex to regulate calcium transfer from the ER to mitochondria $[13,206]$. During cardiac IR, CypD plays a dual role, inducing mitochondrial calcium accumulation and also promoting MPTP pore opening to induce apoptosis [13]. $\mathrm{mPTP}$ opening is a major mechanism responsible for the release of mitochondrial DAMPs into the cytosol and therefore inflammasome activation [207]. Stimulation of mouse macrophages with LPS enhanced mitochondrial damage and induced inflammatory responses, whereas, in macrophages lacking CypD, the LPS-stimulated inflammatory response was suppressed [208]. These findings indicate the direct involvement of MAM in the generation of DAMPs and inflammasome activation in metabolic diseases. Based on this current understanding, a hypothetical model of the effects of mitochondrial DAMPs through MAM is presented in Figure 3. 


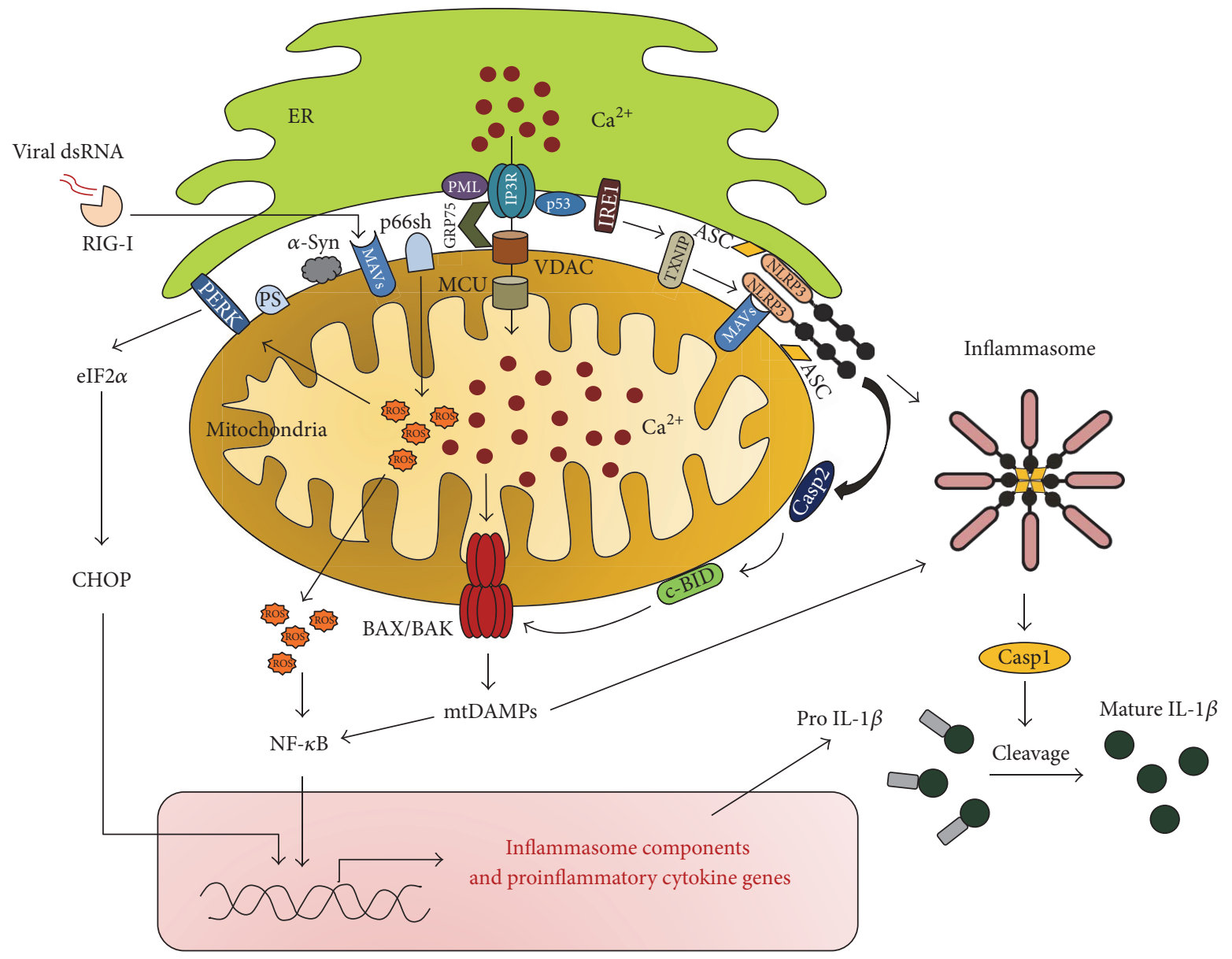

FIGURE 2: Mitochondria-associated ER membrane as an inflammatory signaling hub. Close contact between the endoplasmic reticulum (ER) and mitochondria via mitochondria-associated ER membrane (MAM) formation allows the ER calcium channel IP3R to funnel calcium into mitochondria by forming a complex with the chaperone protein GRP75 and the mitochondrial outer membrane calcium channel VDAC. Then, the inner mitochondrial membrane calcium channel MCU injects calcium into the mitochondrial matrix. Under pathological conditions, elevated ER-mitochondrial interaction promotes calcium accumulation via proteins present at the MAM interface. The MAM-resident proteins PML and p53 control ER calcium release by physically interacting with IP3R. In addition, p66sh amplifies mitochondrial ROS production. Increased cellular ROS activates NF- $\kappa$ B, a master regulator of inflammation, resulting in increased expression of genes encoding numerous proinflammatory cytokines. PERK plays a dual role by tethering ER and mitochondria and detecting ROS production, which triggers its ER stress signaling cascade. In response to ER stress, activated IRE1 promotes NLRP3 through a TXNIPdependent mechanism. NLRP3 detects mitochondrial ROS generation and recruits caspase-2 (Casp2) to mitochondria to cleave BID, forming c-BID, which in turn promotes BAX/BAK-mediated mtDAMP release. NLRP3 activation also promotes recruitment of ASC to MAM, where inflammasome complexes are assembled. Finally, inflammasomes activate caspase-1 (Casp1), which cleaves pro-IL-1 $\beta$ to generate mature IL-1 $\beta$. Foreign pathogen-associated dsDNA is detected by RIG-1, resulting in activation of MAVS and therefore promotion of its downstream inflammatory response. MAVS can also recruit NLRP3 onto mitochondria and promote inflammasome formation, which specifically induces IL- $1 \beta$ production. Other MAM-resident proteins such as presenilins (PS) and $\alpha$-synuclein ( $\alpha$-Syn) play a crucial role in the pathogenesis of Alzheimer's disease and Parkinson's disease, respectively. IP3R: inositol 1,4,5-trisphosphate receptor; MCU: mitochondrial calcium uniporter; GRP75: 75 kDa glucose-regulated protein; VDAC: voltage-dependent anion channel; PERK: pancreatic ER kinase; PML: promyelocytic leukemia protein; p53: tumor protein p53; p66sh: $66 \mathrm{kDa}$ isoform of the growth factor adapter Shc; NF-kB: nuclear factorkappa B; eIF2 $\alpha$ : eukaryotic initiation factor 2 alpha; CHOP: CCAAT-enhancer-binding protein homologous protein; IRE1: inositol-requiring enzyme 1; NLRP3: NACHT, LRR, and PYD domain-containing protein 3; ASC: apoptosis-associated speck-like protein containing a CARD; TXNIP: thioredoxin-interacting protein; IL-1 $\beta$ : interleukin-1 beta; BID: BH3 interacting-domain death agonist; ROS: reactive oxygen species; BAX: Bcl-2-associated X protein; BAK: Bcl-2 homologous antagonist/killer; MAVS: mitochondrial antiviral-signaling protein; RIG-1: retinoic acid-inducible gene-1 protein; mtDAMPs: mitochondrial damage-associated molecular patterns. 
Infection, hypoxia, obesity, diabetes

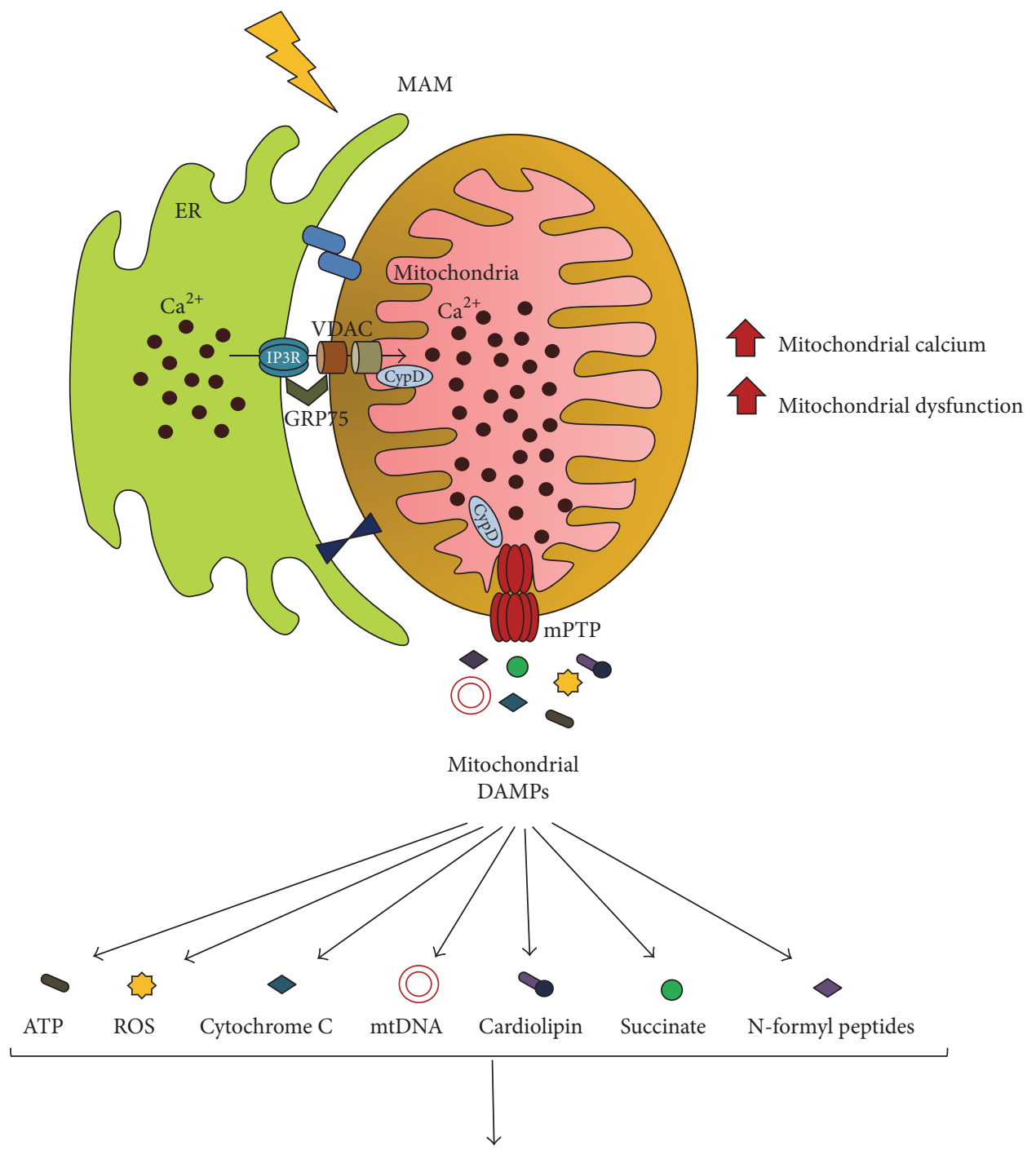

Inflammasome

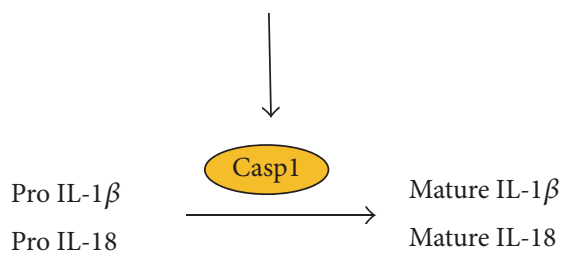

FIGURE 3: A hypothetical model of mitochondrial DAMP induction through mitochondria-associated ER membrane (MAM). Cellular metabolic dysfunction mediated by infection, hypoxia, obesity, and diabetes triggers abnormal association of endoplasmic reticulum (ER) and mitochondria. This increase in MAM formation induces mitochondrial calcium overload and exacerbates mitochondrial ROS generation, leading to mitochondrial permeability transition pore (mPTP) opening. The mitochondrial matrix protein CypD mediates mitochondrial calcium accumulation by physically interacting with the IP3R, GRP75, and VDAC complex at the MAM interface and modulates MPTP pore opening directly. mPTP opening facilitates release of mitochondrial components such as ATP, ROS, cytochrome $\mathrm{C}, \mathrm{mtDNA}$, cardiolipin, succinate, and $\mathrm{N}$-formyl peptides into the cytosol, where they serve as mtDAMPS to activate the inflammasome. Subsequently, inflammasomes activate caspase-1 (Casp1) to induce cleavage and maturation of the proinflammatory cytokines IL- $1 \beta$ and IL18. CypD: cyclophilin D; IP3R: inositol 1,4,5-trisphosphate receptor; GRP75: $75 \mathrm{kDa}$ glucose-regulated protein; VDAC: voltage-dependent anion channel; mtDNA: mitochondrial DNA; IL-1 $\beta$ : interleukin-1 beta; IL-18: interleukin-18; ATP: adenosine triphosphate; ROS: reactive oxygen species; mtDAMPs: mitochondrial damage-associated molecular patterns. 
TABLE 1: MAM-resident proteins linked with metabolic and inflammatory diseases.

\begin{tabular}{|c|c|c|c|c|}
\hline Proteins & MAM formation & Cell/tissue & Diseases & References \\
\hline IP3R1, PACS2 & Promote & Liver & Insulin resistance & {$[6]$} \\
\hline CypD & Promote & Liver & Insulin resistance & {$[23]$} \\
\hline CypD & Promote & Cardiac muscle & Ischemia-reperfusion injury & {$[13]$} \\
\hline GSK- $3 \beta$ & Promote & Cardiac muscle & Ischemia-reperfusion injury & {$[24]$} \\
\hline Mfn2 & Promote & Human airway smooth muscle cells & Asthma & {$[25]$} \\
\hline PML & Promote & Mouse embryonic fibroblast cells (MEFs) & Cancer & {$[20]$} \\
\hline p53 & Promote & Various cancer cells & Cancer & {$[26]$} \\
\hline p66Shc & Promote & MAFs (mouse adult fibroblasts) & Cancer & {$[27]$} \\
\hline PTEN & Promote & HEK-293, MEFs & Cancer & {$[28]$} \\
\hline FATE1 & Inhibit & Cancer cells & Cancer & [29] \\
\hline TMX1 & Promote & Cancer cells, MEFs & Cancer & {$[30]$} \\
\hline FUS & Promote & Neuronal cells & ALS & [31] \\
\hline Presenilins & Promote & Brain & Alzheimer's disease & {$[10,32]$} \\
\hline Parkin & Promote & Brain & Parkinson's disease & [33] \\
\hline$\alpha$-Synuclein & Promote & Brain & Parkinson's disease & {$[34]$} \\
\hline Nogo A & Inhibit & Cardiomyocyte & Ischemia-reperfusion injury & {$[35]$} \\
\hline Nogo B & Inhibit & PASMCs, CASMCs, RASMCs & Pulmonary hypertension & {$[36]$} \\
\hline RyR, VDAC & Promote & Cardiac muscle & Aging & [37] \\
\hline
\end{tabular}

IP3R1: inositol 1,4,5-trisphosphate receptor 1; PACS2: phosphofurin acidic cluster sorting protein 2; CypD: cyclophilin D; GSK-3 $\beta$ : glycogen synthase kinase 3 beta; Mfn2: mitofusin 2; PML: promyelocytic leukemia protein; p53: tumor protein p53; p66sh: $66 \mathrm{kDa}$ isoform of the growth factor adapter Shc; PTEN: phosphatase and tensin homolog; FATE: fetal and adult testis-expressed transcript protein; TMX1: thioredoxin related transmembrane protein 1; FUS: fused in sarcoma; Nogo A and B: reticulon-4/neurite outgrowth inhibitor; RyR: ryanodine receptors; VDAC: voltage-dependent anion channel; ALS: amyotrophic lateral sclerosis; PASMCs: porcine aortic smooth muscle cell; CASMCs: chicken aortic smooth muscle cells; RASMCs: rat aortic smooth muscle cell.

\section{Association of MAM with Metabolic and Inflammatory Diseases}

Metainflammation is a low-grade type of inflammation which is triggered by metabolic dysfunction [209]. Because of the numerous environmental, genetic, and psychosocial factors that promote it, metainflammation is an increasing threat to human health. Many reports have shown a link between inflammation and metabolic diseases such as atherosclerosis, diabetes, cancer, and $\mathrm{AD}[1,210,211]$. Many defects in cellular pathways and cellular organelles have been implicated in the pathogenesis of these diseases. One of the critical common mechanisms is dysfunction of the ER and mitochondria, which are hubs for many signaling pathways. Cross-communication between these two organelles through formation of MAM has also been specifically implicated in many diseases [212]. The following table (Table 1) lists some of the diseases that have been associated with MAM and MAMresident proteins.

\section{Conclusion}

MAM is enriched with master regulator proteins that influence multiple signaling pathways to determine cellular fate. Numerous studies have revealed its association with many pathological conditions ranging from pathogenic infections to diabetes and cancer. All these metabolic diseases are mediated through low-grade inflammation due to harmful environmental factors, especially overconsumption of an unhealthy diet. ER stress and mitochondrial stress are the first signs of cellular stress, and prolonged stress in these organelles leads to deterioration in their normal function, which can lead to the development of complex metabolic diseases. MAM provides a platform for cross-talk between the ER and mitochondria, allowing rapid exchange of biological molecules to maintain cellular health. However, abnormal exchange of these cellular metabolites, such as lipids and calcium, due to excess nutrient intake, hampers mitochondrial health and promotes increased production of ROS and release of mitochondrial DAMPs into the cytosol. These molecules are recognized by inflammasome components, triggering increases in proinflammatory cytokine secretion, followed by activation and sensitization of immune cells to initiate inflammatory responses.

In this review, we have elaborated the pivotal role of MAM in the instigation of metainflammation and the development of complex metabolic diseases. Frequent reevaluation and review of independent findings are needed to assist with the development of future therapeutics targeting these mechanisms. Overall, MAM has great potential to provide future therapeutic targets for a wide range of metabolic and inflammatory diseases.

\section{Competing Interests}

The authors declare that there is no conflict of interests regarding the publication of this paper. 


\section{Authors' Contributions}

All authors equally contributed to this work.

\section{Acknowledgments}

This research was supported by the Bio \& Medical Technology Development Program of the NRF funded by the Korean government, MSIP (2016M3A9B6902872), and a grant of the Korea Health Technology R\&D Project through the Korea Health Industry Development Institute (KHIDI), funded by the Ministry of Health \& Welfare, Republic of Korea (Grant no. HI16C1501).

\section{References}

[1] C. N. Lumeng and A. R. Saltiel, "Inflammatory links between obesity and metabolic disease," Journal of Clinical Investigation, vol. 121, no. 6, pp. 2111-2117, 2011.

[2] R. G. Baker, M. S. Hayden, and S. Ghosh, "NF- $\kappa$ B, inflammation, and metabolic disease," Cell Metabolism, vol. 13, no. 1, pp. $11-22,2011$.

[3] J.-A. Kim, Y. Wei, and J. R. Sowers, "Role of mitochondrial dysfunction in insulin resistance," Circulation Research, vol. 102, no. 4, pp. 401-414, 2008.

[4] G. Boden, "Endoplasmic reticulum stress: another link between obesity and insulin resistance/inflammation?" Diabetes, vol. 58, no. 3, pp. 518-519, 2009.

[5] S. Fu, L. Yang, P. Li et al., "Aberrant lipid metabolism disrupts calcium homeostasis causing liver endoplasmic reticulum stress in obesity," Nature, vol. 473, no. 7348, pp. 528-531, 2011.

[6] A. P. Arruda, B. M. Pers, G. Parlakgül, E. Güney, K. Inouye, and G. S. Hotamisligil, "Chronic enrichment of hepatic endoplasmic reticulum-mitochondria contact leads to mitochondrial dysfunction in obesity," Nature Medicine, vol. 20, no. 12, pp. 14271435, 2014.

[7] R. Zhou, A. S. Yazdi, P. Menu, and J. Tschopp, "A role for mitochondria in NLRP3 inflammasome activation," Nature, vol. 469, no. 7329, pp. 221-226, 2011.

[8] R. Rizzuto, P. Pinton, W. Carrington et al., "Close contacts with the endoplasmic reticulum as determinants of mitochondrial $\mathrm{Ca}^{2+}$ responses," Science, vol. 280, no. 5370, pp. 1763-1766, 1998.

[9] C.-H. Wang, T.-F. Tsai, and Y.-H. Wei, "Role of mitochondrial dysfunction and dysregulation of $\mathrm{Ca}^{2+}$ homeostasis in insulin insensitivity of mammalian cells," Annals of the New York Academy of Sciences, vol. 1350, pp. 66-76, 2015.

[10] E. Area-Gomez, M. Del Carmen Lara Castillo, M. D. Tambini et al., "Upregulated function of mitochondria-associated ER membranes in Alzheimer disease," EMBO Journal, vol. 31, no. 21, pp. 4106-4123, 2012.

[11] E. Zampese, C. Fasolato, M. J. Kipanyula, M. Bortolozzi, T. Pozzan, and P. Pizzo, "Presenilin 2 modulates endoplasmic reticulum (ER)-mitochondria interactions and $\mathrm{Ca}^{2+}$ cross-talk," Proceedings of the National Academy of Sciences of the United States of America, vol. 108, no. 7, pp. 2777-2782, 2011.

[12] L. Hedskog, C. M. Pinho, R. Filadi et al., "Modulation of the endoplasmic reticulum-mitochondria interface in Alzheimer's disease and related models," Proceedings of the National Academy of Sciences of the United States of America, vol. 110, no. 19, pp. 7916-7921, 2013.
[13] M. Paillard, E. Tubbs, P.-A. Thiebaut et al., "Depressing mitochondria-reticulum interactions protects cardiomyocytes from lethal hypoxia-reoxygenation injury," Circulation, vol. 128, no. 14, pp. 1555-1565, 2013.

[14] J. E. Vance and D. E. Vance, "Specific pools of phospholipids are used for lipoprotein secretion by cultured rat hepatocytes," Journal of Biological Chemistry, vol. 261, no. 10, pp. 4486-4491, 1986.

[15] M. R. Duchen, " $\mathrm{Ca}^{2+}$-dependent changes in the mitochondrial energetics in single dissociated mouse sensory neurons," Biochemical Journal, vol. 283, no. 1, pp. 41-50, 1992.

[16] R. Bravo, J. M. Vicencio, V. Parra et al., "Increased ER-mitochondrial coupling promotes mitochondrial respiration and bioenergetics during early phases of ER stress," Journal of Cell Science, vol. 124, no. 13, pp. 2143-2152, 2011.

[17] T. E. Gunter, D. I. Yule, K. K. Gunter, R. A. Eliseev, and J. D. Salter, "Calcium and mitochondria," FEBS Letters, vol. 567, no. 1, pp. 96-102, 2004.

[18] L. S. Jouaville, P. Pinton, C. Bastianutto, G. A. Rutter, and R. Rizzuto, "Regulation of mitochondrial ATP synthesis by calcium: evidence for a long-term metabolic priming," Proceedings of the National Academy of Sciences of the United States of America, vol. 96, no. 24, pp. 13807-13812, 1999.

[19] C. Betz, D. Stracka, C. Prescianotto-Baschong, M. Frieden, N. Demaurex, and M. N. Hall, "mTOR complex 2-Akt signaling at mitochondria-associated endoplasmic reticulum membranes (MAM) regulates mitochondrial physiology," Proceedings of the National Academy of Sciences of the United States of America, vol. 110, no. 31, pp. 12526-12534, 2013.

[20] C. Giorgi, K. Ito, H.-K. Lin et al., "PML regulates apoptosis at endoplasmic reticulum by modulating calcium release," Science, vol. 330, no. 6008, pp. 1247-1251, 2010.

[21] Y. Wei, D. Wang, C. L. Gentile, and M. J. Pagliassotti, "Reduced endoplasmic reticulum luminal calcium links saturated fatty acid-mediated endoplasmic reticulum stress and cell death in liver cells," Molecular and Cellular Biochemistry, vol. 331, no. 12, pp. 31-40, 2009.

[22] A. Raturi and T. Simmen, "Where the endoplasmic reticulum and the mitochondrion tie the knot: the mitochondria-associated membrane (MAM)," Biochimica et Biophysica ActaMolecular Cell Research, vol. 1833, no. 1, pp. 213-224, 2013.

[23] J. Rieusset, J. Fauconnier, M. Paillard et al., "Disruption of calcium transfer from ER to mitochondria links alterations of mitochondria-associated ER membrane integrity to hepatic insulin resistance," Diabetologia, vol. 59, no. 3, pp. 614-623, 2016.

[24] L. Gomez, P.-A. Thiebaut, M. Paillard et al., "The SR/ER-mitochondria calcium crosstalk is regulated by GSK $3 \beta$ during reperfusion injury," Cell Death \& Differentiation, vol. 22, no. 11, p. 1890, 2015.

[25] P. Delmotte and G. C. Sieck, "Interaction between endoplasmic/sarcoplasmic reticulum stress (ER/SR stress), mitochondrial signaling and $\mathrm{Ca}(2+)$ regulation in airway smooth muscle (ASM)," Canadian Journal of Physiology and Pharmacology, vol. 93, no. 2, pp. 97-110, 2015.

[26] C. Giorgi, M. Bonora, G. Sorrentino et al., "P53 at the endoplasmic reticulum regulates apoptosis in a $\mathrm{Ca}^{2+}$-dependent manner," Proceedings of the National Academy of Sciences of the United States of America, vol. 112, no. 6, pp. 1779-1784, 2015.

[27] M. Lebiedzinska, J. Duszynski, R. Rizzuto, P. Pinton, and M. R. Wieckowski, "Age-related changes in levels of p66Shc and serine 36-phosphorylated p66Shc in organs and mouse tissues," 
Archives of Biochemistry and Biophysics, vol. 486, no. 1, pp. 7380, 2009.

[28] A. Bononi, M. Bonora, S. Marchi et al., "Identification of PTEN at the ER and MAMs and its regulation of $\mathrm{Ca}^{2+}$ signaling and apoptosis in a protein phosphatase-dependent manner," Cell Death and Differentiation, vol. 20, no. 12, pp. 1631-1643, 2013.

[29] M. Doghman-Bouguerra, V. Granatiero, S. Sbiera et al., "FATE1 antagonizes calcium- and drug-induced apoptosis by uncoupling ER and mitochondria," EMBO Reports, vol. 17, no. 9, pp. 1264-1280, 2016.

[30] A. Raturi, T. Gutiérrez, C. Ortiz-Sandoval et al., "TMX1 determines cancer cell metabolism as a thiol-based modulator of ERmitochondria $\mathrm{Ca}^{2+}$ flux," The Journal of Cell Biology, vol. 214, no. 4, pp. 433-444, 2016.

[31] R. Stoica, S. Paillusson, P. Gomez-Suaga et al., "ALS/FTD-associated FUS activates GSK $-3 \beta$ to disrupt the VAPB-PTPIP51 interaction and ER-mitochondria associations," EMBO Reports, vol. 17, no. 9, pp. 1237-1359, 2016.

[32] R. Filadi, E. Greotti, G. Turacchio, A. Luini, T. Pozzan, and P. Pizzo, "Presenilin 2 modulates endoplasmic reticulummitochondria coupling by tuning the antagonistic effect of mitofusin 2," Cell Reports, vol. 15, no. 10, pp. 2226-2238, 2016.

[33] C. A. Gautier, Z. Erpapazoglou, F. Mouton-Liger et al., “The endoplasmic reticulum-mitochondria interface is perturbed in PARK2 knockout mice and patients with PARK2 mutations," Human Molecular Genetics, vol. 25, no. 14, pp. 2972-2984, 2016.

[34] C. Guardia-Laguarta, E. Area-Gomez, C. Rüb et al., “ $\alpha$ Synuclein is localized to mitochondria-associated ER membranes," The Journal of Neuroscience, vol. 34, no. 1, pp. 249-259, 2014.

[35] J. P. Sarkey, M. Chu, M. McShane et al., "Nogo-A knockdown inhibits hypoxia/reoxygenation-induced activation of mitochondrial-dependent apoptosis in cardiomyocytes," Journal of Molecular and Cellular Cardiology, vol. 50, no. 6, pp. 1044-1055, 2011.

[36] G. Sutendra, P. Dromparis, P. Wright et al., "The role of nogo and the mitochondria-endoplasmic reticulum unit in pulmonary hypertension," Science Translational Medicine, vol. 3, no. 88, Article ID 88ra55, 2011.

[37] C. Fernandez-Sanz, M. Ruiz-Meana, E. Miro-Casas et al., "Defective sarcoplasmic reticulum-mitochondria calcium exchange in aged mouse myocardium," Cell Death \& Disease, vol. 5, no. 12, Article ID e1573, 2014.

[38] J. Mandl, T. Mészáros, G. Bánhegyi, L. Hunyady, and M. Csala, "Endoplasmic reticulum: nutrient sensor in physiology and pathology," Trends in Endocrinology and Metabolism, vol. 20, no. 4, pp. 194-201, 2009.

[39] E. F. Corbett, K. Oikawa, P. Francois et al., "Ca ${ }^{2+}$ regulation of interactions between endoplasmic reticulum chaperones," Journal of Biological Chemistry, vol. 274, no. 10, pp. 6203-6211, 1999.

[40] M. C. Ashby and A. V. Tepikin, "ER calcium and the functions of intracellular organelles," Seminars in Cell and Developmental Biology, vol. 12, no. 1, pp. 11-17, 2001.

[41] M. J. Phillips and G. K. Voeltz, "Structure and function of ER membrane contact sites with other organelles," Nature Reviews Molecular Cell Biology, vol. 17, no. 2, pp. 69-82, 2016.

[42] A. D. Garg, A. Kaczmarek, O. Krysko, P. Vandenabeele, D. V. Krysko, and P. Agostinis, "ER stress-induced inflammation: does it aid or impede disease progression?" Trends in Molecular Medicine, vol. 18, no. 10, pp. 589-598, 2012.
[43] M. Wang and R. J. Kaufman, "The impact of the endoplasmic reticulum protein-folding environment on cancer development," Nature Reviews Cancer, vol. 14, no. 9, pp. 581-597, 2014.

[44] G. S. Hotamisligil, "Endoplasmic reticulum stress and the inflammatory basis of metabolic disease," Cell, vol. 140, no. 6, pp. 900-917, 2010.

[45] H. Yoshida, T. Matsui, A. Yamamoto, T. Okada, and K. Mori, "XBP1 mRNA is induced by ATF6 and spliced by IRE1 in response to ER stress to produce a highly active transcription factor," Cell, vol. 107, no. 7, pp. 881-891, 2001.

[46] L. Zeng, Y.-P. Liu, H. Sha, H. Chen, L. Qi, and J. A. Smith, "XBP1 couples endoplasmic reticulum stress to augmented IFN- $\beta$ induction via a cis-acting enhancer in macrophages," Journal of Immunology, vol. 185, no. 4, pp. 2324-2330, 2010.

[47] S. Kim, Y. Joe, H. J. Kim et al., "Endoplasmic reticulum stressinduced IRE1 $\alpha$ activation mediates cross-talk of GSK-3 $\beta$ and XBP-1 to regulate inflammatory cytokine production," Journal of Immunology, vol. 194, no. 9, pp. 4498-4506, 2015.

[48] G. P. Meares, Y. Liu, R. Rajbhandari et al., "Perk-dependent activation of JAK1 and STAT3 contributes to endoplasmic reticulum stress-induced inflammation," Molecular and Cellular Biology, vol. 34, no. 20, pp. 3911-3925, 2014.

[49] J. C. Goodall, C. Wu, Y. Zhang et al., "Endoplasmic reticulum stress-induced transcription factor, CHOP, is crucial for dendritic cell IL-23 expression," Proceedings of the National Academy of Sciences of the United States of America, vol. 107, no. 41, pp. 17698-17703, 2010.

[50] M. W. L. Teng, E. P. Bowman, J. J. McElwee et al., "IL-12 and IL23 cytokines: from discovery to targeted therapies for immunemediated inflammatory diseases," Nature Medicine, vol. 21, no. 7, pp. 719-729, 2015.

[51] J. Rao, S. Yue, Y. Fu et al., "ATF6 mediates a pro-inflammatory synergy between ER stress and TLR activation in the pathogenesis of liver ischemia-reperfusion injury," American Journal of Transplantation, vol. 14, no. 7, pp. 1552-1561, 2014.

[52] J. R. Friedman and J. Nunnari, "Mitochondrial form and function," Nature, vol. 505, no. 7483, pp. 335-343, 2014.

[53] K. Asehnoune, D. Strassheim, S. Mitra, J. Y. Kim, and E. Abraham, "Involvement of reactive oxygen species in toll-like receptor 4-dependent activation of NF- $\kappa$ B," Journal of Immunology, vol. 172, no. 4, pp. 2522-2529, 2004.

[54] M. J. López-Armada, R. R. Riveiro-Naveira, C. VaamondeGarcía, and M. N. Valcárcel-Ares, "Mitochondrial dysfunction and the inflammatory response," Mitochondrion, vol. 13, no. 2, pp. 106-118, 2013.

[55] S. Agarwal, W. A. Van Cappellen, A. Guénolé et al., "ATPdependent and independent functions of Rad54 in genome maintenance," The Journal of Cell Biology, vol. 192, no. 5, pp. 735750, 2011.

[56] K. Shimada, T. R. Crother, J. Karlin et al., "Oxidized mitochondrial DNA activates the NLRP3 inflammasome during apoptosis," Immunity, vol. 36, no. 3, pp. 401-414, 2012.

[57] J. Tschopp, “Mitochondria: Sovereign of inflammation?" European Journal of Immunology, vol. 41, no. 5, pp. 1196-1202, 2011.

[58] F. Hou, L. Sun, H. Zheng, B. Skaug, Q. X. Jiang, and Z. J. Chen, "MAVS forms functional prion-like aggregates to activate and propagate antiviral innate immune response," Cell, vol. 146, no. 3, pp. 448-461, 2011.

[59] S. H. Kwak, K. S. Park, K.-U. Lee, and H. K. Lee, "Mitochondrial metabolism and diabetes," Journal of Diabetes Investigation, vol. 1, no. 5, pp. 161-169, 2010. 
[60] C. M. Larsen, M. Faulenbach, A. Vaag et al., "Interleukin-1receptor antagonist in type 2 diabetes mellitus," New England Journal of Medicine, vol. 356, no. 15, pp. 1517-1526, 2007.

[61] L. C. Harty, M. Biniecka, J. O’Sullivan et al., "Mitochondrial mutagenesis correlates with the local inflammatory environment in arthritis," Annals of the Rheumatic Diseases, vol. 71, no. 4, pp. 582-588, 2012.

[62] M. N. Valcárcel-Ares, R. R. Riveiro-Naveira, C. VaamondeGarcía et al., "Mitochondrial dysfunction promotes and aggravates the inflammatory response in normal human synoviocytes," Rheumatology, vol. 53, no. 7, Article ID keu016, pp. 13321343, 2014.

[63] H. Nakayama and K. Otsu, "Translation of hemodynamic stress to sterile inflammation in the heart," Trends in Endocrinology and Metabolism, vol. 24, no. 11, pp. 546-553, 2013.

[64] T. Oka, S. Hikoso, O. Yamaguchi et al., "Mitochondrial DNA that escapes from autophagy causes inflammation and heart failure," Nature, vol. 485, no. 7397, pp. 251-255, 2012.

[65] K. Kuchler, G. Daum, and F. Paltauf, "Subcellular and submitochondrial localization of phospholipid-synthesizing enzymes in Saccharomyces cerevisiae," Journal of Bacteriology, vol. 165, no. 3, pp. 901-910, 1986.

[66] J. E. Vance, "Phospholipid synthesis in a membrane fraction associated with mitochondria," Journal of Biological Chemistry, vol. 265, no. 13, pp. 7248-7256, 1990.

[67] R. Kojima, T. Endo, and Y. Tamura, "A phospholipid transfer function of ER-mitochondria encounter structure revealed in vitro," Scientific Reports, vol. 6, Article ID 30777, 2016.

[68] D. Naon and L. Scorrano, "At the right distance: ER-mitochondria juxtaposition in cell life and death," Biochimica et Biophysica Acta, vol. 1843, no. 10, pp. 2184-2194, 2014.

[69] J. Schiller, O. Zschörnig, M. Petković, M. Müller, J. Arnhold, and K. Arnold, "Lipid analysis of human HDL and LDL by MALDI-TOF mass spectrometry and ${ }^{31}$ P-NMR," Journal of Lipid Research, vol. 42, no. 9, pp. 1501-1508, 2001.

[70] Z. Li, L. B. Agellon, T. M. Allen et al., "The ratio of phosphatidylcholine to phosphatidylethanolamine influences membrane integrity and steatohepatitis," Cell Metabolism, vol. 3, no. 5, pp. 321-331, 2006.

[71] M. Prasad, J. Kaur, K. J. Pawlak, M. Bose, R. M. Whittal, and H. S. Bose, "Mitochondria-associated endoplasmic reticulum membrane (MAM) regulates steroidogenic activity via steroidogenic acute regulatory protein (StAR)-voltage-dependent anion channel 2 (VDAC2) interaction," Journal of Biological Chemistry, vol. 290, no. 5, pp. 2604-2616, 2015.

[72] G. Szabadkai, K. Bianchi, P. Várnai et al., "Chaperone-mediated coupling of endoplasmic reticulum and mitochondrial $\mathrm{Ca}^{2+}$ channels," Journal of Cell Biology, vol. 175, no. 6, pp. 901-911, 2006.

[73] C. K. Min, D. R. Yeom, K.-E. Lee et al., "Coupling of ryanodine receptor 2 and voltage-dependent anion channel 2 is essential for $\mathrm{Ca} 2+$ transfer from the sarcoplasmic reticulum to the mitochondria in the heart," Biochemical Journal, vol. 447, no. 3, pp. 371-379, 2012.

[74] R. Rizzuto, D. De Stefani, A. Raffaello, and C. Mammucari, "Mitochondria as sensors and regulators of calcium signalling," Nature Reviews Molecular Cell Biology, vol. 13, no. 9, pp. 566578, 2012.
[75] G. Báthori, G. Csordás, C. Garcia-Perez, E. Davies, and G. Hajnóczky, "Ca2+-dependent control of the permeability properties of the mitochondrial outer membrane and voltagedependent anion-selective channel (VDAC)," Journal of Biological Chemistry, vol. 281, no. 25, pp. 17347-17358, 2006.

[76] Y. Kirichok, G. Krapivinsky, and D. E. Clapham, "The mitochondrial calcium uniporter is a highly selective ion channel," Nature, vol. 427, no. 6972, pp. 360-364, 2004.

[77] R. M. Denton, "Regulation of mitochondrial dehydrogenases by calcium ions," Biochimica et Biophysica Acta-Bioenergetics, vol. 1787, no. 11, pp. 1309-1316, 2009.

[78] A. J. Kowaltowski, N. C. de Souza-Pinto, R. F. Castilho, and A. E. Vercesi, "Mitochondria and reactive oxygen species," Free Radical Biology and Medicine, vol. 47, no. 4, pp. 333-343, 2009.

[79] S. Hurst, J. Hoek, and S. Sheu, "Mitochondrial $\mathrm{Ca}^{2+}$ and regulation of the permeability transition pore," Journal of Bioenergetics and Biomembranes, pp. 1-12, 2016.

[80] J. R. Testa and P. N. Tsichlis, "AKT signaling in normal and malignant cells," Oncogene, vol. 24, no. 50, pp. 7391-7393, 2005.

[81] S. Marchi, M. Marinello, A. Bononi et al., "Selective modulation of subtype III $\mathrm{IP}_{3} \mathrm{R}$ by Akt regulates $\mathrm{ER} \mathrm{Ca}^{2+}$ release and apoptosis," Cell Death \& Disease, vol. 3, no. 5, article e304, 2012.

[82] M. T. Khan, L. Wagner II, D. I. Yule, C. Bhanumathy, and S. K. Joseph, "Akt kinase phosphorylation of inositol 1,4,5-trisphosphate receptors," Journal of Biological Chemistry, vol. 281, no. 6, pp. 3731-3737, 2006.

[83] S. Marchi, A. Rimessi, C. Giorgi et al., "Akt kinase reducing endoplasmic reticulum $\mathrm{Ca} 2+$ release protects cells from $\mathrm{Ca} 2+-$ dependent apoptotic stimuli," Biochemical and Biophysical Research Communications, vol. 375, no. 4, pp. 501-505, 2008.

[84] T. Maehama and J. E. Dixon, “The tumor suppressor, PTEN/ MMAC1, dephosphorylates the lipid second messenger, phosphatidylinositol 3,4,5-trisphosphate," Journal of Biological Chemistry, vol. 273, no. 22, pp. 13375-13378, 1998.

[85] M. Butler, R. A. McKay, I. J. Popoff et al., "Specific inhibition of PTEN expression reverses hyperglycemia in diabetic mice," Diabetes, vol. 51, no. 4, pp. 1028-1034, 2002.

[86] N. Wijesekara, D. Konrad, M. Eweida et al., "Muscle-specific Pten deletion protects against insulin resistance and diabetes," Molecular and Cellular Biology, vol. 25, no. 3, pp. 1135-1145, 2005.

[87] G. P. Lobo, K. A. Waite, S. M. Planchon, T. Romigh, J. A. Houghton, and C. Eng, "ATP modulates PTEN subcellular localization in multiple cancer cell lines," Human Molecular Genetics, vol. 17, no. 18, pp. 2877-2885, 2008.

[88] L. Zu, X. Zheng, B. Wang et al., "Ischemic preconditioning attenuates mitochondrial localization of PTEN induced by ischemia-reperfusion," American Journal of Physiology-Heart and Circulatory Physiology, vol. 300, no. 6, pp. H2177-H2186, 2011.

[89] A. Bononi and P. Pinton, "Study of PTEN subcellular localization," Methods, vol. 77-78, pp. 92-103, 2015.

[90] N. Embi, D. B. Rylatt, and P. Cohen, "Glycogen synthase kinase3 from rabbit skeletal muscle. Separation from cyclic-AMPdependent protein kinase and phosphorylase kinase," European Journal of Biochemistry, vol. 107, no. 2, pp. 519-527, 1980.

[91] J. R. Woodgett and P. Cohen, "Multisite phosphorylation of glycogen synthase: molecular basis for the substrate specificity of glycogen synthease kinase-3 and casein kinase-II (glycogen synthase kinase-5)," Biochimica et Biophysica Acta-Protein Structure and Molecular, vol. 788, no. 3, pp. 339-347, 1984. 
[92] H. Tong, K. Imahashi, C. Steenbergen, and E. Murphy, "Phosphorylation of glycogen synthase kinase- $3 \beta$ during preconditioning through a phosphatidylinositol-3-kinase-dependent pathway is cardioprotective," Circulation Research, vol. 90, no. 4, pp. 377-379, 2002.

[93] M. Nishihara, T. Miura, T. Miki et al., "Modulation of the mitochondrial permeability transition pore complex in GSK-3 $\beta$ mediated myocardial protection," Journal of Molecular and Cellular Cardiology, vol. 43, no. 5, pp. 564-570, 2007.

[94] R. A. Cairns, I. S. Harris, and T. W. Mak, "Regulation of cancer cell metabolism," Nature Reviews Cancer, vol. 11, no. 2, pp. 8595, 2011.

[95] K. L. Eales, K. E. Hollinshead, and D. A. Tennant, "Hypoxia and metabolic adaptation of cancer cells," Oncogenesis, vol. 5, no. 1, article e190, 2016.

[96] D. A. Tennant, R. V. Durán, H. Boulahbel, and E. Gottlieb, "Metabolic transformation in cancer," Carcinogenesis, vol. 30, no. 8, pp. 1269-1280, 2009.

[97] H. K. Eltzschig and P. Carmeliet, "Hypoxia and inflammation," New England Journal of Medicine, vol. 364, no. 7, pp. 656-665, 2011.

[98] K. Bartels, A. Grenz, and H. K. Eltzschig, "Hypoxia and inflammation are two sides of the same coin," Proceedings of the National Academy of Sciences of the United States of America, vol. 110, no. 46, pp. 18351-18352, 2013.

[99] M. Grocott, H. Montgomery, and A. Vercueil, "High-altitude physiology and pathophysiology: implications and relevance for intensive care medicine," Critical Care, vol. 11, no. 1, article no. 203, 2007.

[100] G. Hartmann, M. Tschöp, R. Fischer et al., "High altitude increases circulating interleukin-6, interleukin-1 receptor antagonist and C-reactive protein," Cytokine, vol. 12, no. 3, pp. 246-252, 2000.

[101] J. Biddlestone, D. Bandarra, and S. Rocha, "The role of hypoxia in inflammatory disease (Review)," International Journal of Molecular Medicine, vol. 35, no. 4, pp. 859-869, 2015.

[102] D. Song, G. Fang, S. Mao et al., "Chronic intermittent hypoxia induces atherosclerosis by NF- $\kappa \mathrm{B}$-dependent mechanisms," Biochimica et Biophysica Acta (BBA)-Molecular Basis of Disease, vol. 1822, no. 11, pp. 1650-1659, 2012.

[103] V. Savransky, A. Nanayakkara, J. Li et al., "Chronic intermittent hypoxia induces atherosclerosis," American Journal of Respiratory and Critical Care Medicine, vol. 175, no. 12, pp. 1290-1297, 2007.

[104] S. P. Weisberg, D. McCann, M. Desai, M. Rosenbaum, R. L. Leibel, and A. W. Ferrante Jr., "Obesity is associated with macrophage accumulation in adipose tissue," Journal of Clinical Investigation, vol. 112, no. 12, pp. 1796-1808, 2003.

[105] K. Makki, P. Froguel, and I. Wolowczuk, "Adipose tissue in obesity-related inflammation and insulin resistance: cells, cytokines, and chemokines," ISRN Inflammation, vol. 2013, Article ID 139239, 12 pages, 2013.

[106] T. Skurk, C. Alberti-Huber, C. Herder, and H. Hauner, "Relationship between adipocyte size and adipokine expression and secretion," Journal of Clinical Endocrinology and Metabolism, vol. 92, no. 3, pp. 1023-1033, 2007.

[107] T. Yamauchi, J. Kamon, H. Waki et al., "Globular adiponectin protected ob/ob mice from diabetes and ApoE-deficient mice from atherosclerosis," The Journal of Biological Chemistry, vol. 278, no. 4, pp. 2461-2468, 2003.
[108] Y. Arita, S. Kihara, N. Ouchi et al., "Paradoxical decrease of an adipose-specific protein, adiponectin, in obesity," Biochemical and Biophysical Research Communications, vol. 257, no. 1, pp. 79-83, 1999.

[109] K. Asayama, H. Hayashibe, K. Dobashi et al., "Decrease in serum adiponectin level due to obesity and visceral fat accumulation in children," Obesity Research, vol. 11, no. 9, pp. 1072-1079, 2003.

[110] J. Ye, Z. Gao, J. Yin, and Q. He, "Hypoxia is a potential risk factor for chronic inflammation and adiponectin reduction in adipose tissue of ob/ob and dietary obese mice," American Journal of Physiology-Endocrinology and Metabolism, vol. 293, no. 4, pp. E1118-E1128, 2007.

[111] N. Hosogai, A. Fukuhara, K. Oshima et al., "Adipose tissue hypoxia in obesity and its impact on adipocytokine dysregulation," Diabetes, vol. 56, no. 4, pp. 901-911, 2007.

[112] B. Chen, K. S. L. Lam, Y. Wang et al., "Hypoxia dysregulates the production of adiponectin and plasminogen activator inhibitor1 independent of reactive oxygen species in adipocytes," Biochemical and Biophysical Research Communications, vol. 341, no. 2, pp. 549-556, 2006.

[113] G. Zappalà and M. M. Rechler, "IGFBP-3, hypoxia and TNF- $\alpha$ inhibit adiponectin transcription," Biochemical and Biophysical Research Communications, vol. 382, no. 4, pp. 785-789, 2009.

[114] L. Liu, D. Feng, G. Chen et al., "Mitochondrial outer-membrane protein FUNDC1 mediates hypoxia-induced mitophagy in mammalian cells," Nature Cell Biology, vol. 14, no. 2, pp. 177-185, 2012.

[115] W. Wu, C. Lin, K. Wu et al., "FUNDC1 regulates mitochondrial dynamics at the ER-mitochondrial contact site under hypoxic conditions," The EMBO Journal, vol. 35, no. 13, pp. 1368-1384, 2016.

[116] M. Liesa and O. S. Shirihai, "Mitochondrial dynamics in the regulation of nutrient utilization and energy expenditure," Cell Metabolism, vol. 17, no. 4, pp. 491-506, 2013.

[117] S. L. Archer, "Mitochondrial dynamics-mitochondrial fission and fusion in human diseases," The New England Journal of Medicine, vol. 369, no. 23, pp. 2236-2251, 2013.

[118] T. Koshiba, S. A. Detmer, J. T. Kaiser, H. Chen, J. M. McCaffery, and D. C. Chan, "Structural basis of mitochondrial tethering by mitofusin complexes," Science, vol. 305, no. 5685, pp. 858-862, 2004.

[119] H. Chen, S. A. Detmer, A. J. Ewald, E. E. Griffin, S. E. Fraser, and D. C. Chan, "Mitofusins Mfn1 and Mfn2 coordinately regulate mitochondrial fusion and are essential for embryonic development," Journal of Cell Biology, vol. 160, no. 2, pp. 189200, 2003.

[120] Y. Eura, N. Ishihara, S. Yokota, and K. Mihara, "Two mitofusin proteins, mammalian homologues of FZO, with distinct functions are both required for mitochondrial fusion," Journal of Biochemistry, vol. 134, no. 3, pp. 333-344, 2003.

[121] O. M. De Brito and L. Scorrano, "Mitofusin 2 tethers endoplasmic reticulum to mitochondria," Nature, vol. 456, no. 7222, pp. 605-610, 2008.

[122] N. S. Leal, B. P. Schreiner, C. M. Pinho et al., "Mitofusin-2 knockdown increases ER-mitochondria contact and decreases amyloid beta-peptide production," Journal of Cellular and Molecular Medicine, vol. 20, no. 9, pp. 1686-1695, 2016.

[123] R. Filadi, E. Greotti, G. Turacchio, A. Luini, T. Pozzan, and P. Pizzo, "Mitofusin 2 ablation increases endoplasmic reticulummitochondria coupling," Proceedings of the National Academy 
of Sciences of the United States of America, vol. 112, no. 17, pp. E2174-E2181, 2015.

[124] P. Cosson, A. Marchetti, M. Ravazzola, and L. Orci, "Mitofusin2 independent juxtaposition of endoplasmic reticulum and mitochondria: an ultrastructural study," PLOS ONE, vol. 7, no. 9, Article ID e46293, 2012.

[125] D. Naon, M. Zaninello, M. Giacomello et al., "Critical reappraisal confirms that Mitofusin 2 is an endoplasmic reticulummitochondria tether," Proceedings of the National Academy of Sciences of the United States of America, vol. 113, no. 40, pp. 11249-11254, 2016.

[126] E. Schrepfer and L. Scorrano, "Mitofusins, from mitochondria to metabolism," Molecular Cell, vol. 61, no. 5, pp. 683-694, 2016.

[127] K. N. Papanicolaou, G. A. Ngoh, E. R. Dabkowski et al., "Cardiomyocyte deletion of mitofusin-1 leads to mitochondrial fragmentation and improves tolerance to ROS-induced mitochondrial dysfunction and cell death," American Journal of Physiology-Heart and Circulatory Physiology, vol. 302, no. 1, pp. H167-H179, 2012.

[128] K.-S. Park, A. Wiederkehr, and C. B. Wollheim, "Defective mitochondrial function and motility due to mitofusin 1 overexpression in insulin secreting cells," Korean Journal of Physiology and Pharmacology, vol. 16, no. 1, pp. 71-77, 2012.

[129] S. Züchner, I. V. Mersiyanova, M. Muglia et al., "Mutations in the mitochondrial GTPase mitofusin 2 cause Charcot-MarieTooth neuropathy type 2A," Nature Genetics, vol. 36, no. 5, pp. 449-451, 2004.

[130] S. A. Detmer and D. C. Chan, "Complementation between mouse Mfn1 and Mfn2 protects mitochondrial fusion defects caused by CMT2A disease mutations," Journal of Cell Biology, vol. 176, no. 4, pp. 405-414, 2007.

[131] D. Bach, D. Naon, S. Pich et al., "Expression of $M f n 2$, the Charcot-Marie-Tooth neuropathy type $2 \mathrm{~A}$ gene, in human skeletal muscle: effects of type 2 diabetes, obesity, weight loss, and the regulatory role of tumor necrosis factor $\alpha$ and interleukin-6," Diabetes, vol. 54, no. 9, pp. 2685-2693, 2005.

[132] K.-X. Gan, C. Wang, J.-H. Chen, C.-J. Zhu, and G.-Y. Song, "Mitofusin-2 ameliorates high-fat diet-induced insulin resistance in liver of rats," World Journal of Gastroenterology, vol. 19, no. 10, pp. 1572-1581, 2013.

[133] D. Sebastián, M. I. Hernández-Alvarez, J. Segalés et al., "Mitofusin 2 (Mfn2) links mitochondrial and endoplasmic reticulum function with insulin signaling and is essential for normal glucose homeostasis," Proceedings of the National Academy of Sciences of the United States of America, vol. 109, no. 14, pp. 55235528, 2012.

[134] S. Pich, D. Bach, P. Briones et al., "The Charcot-MarieTooth type 2A gene product, Mfn2, up-regulates fuel oxidation through expression of OXPHOS system," Human Molecular Genetics, vol. 14, no. 11, pp. 1405-1415, 2005.

[135] K. N. Papanicolaou, R. J. Khairallah, G. A. Ngoh et al., "Mitofusin-2 maintains mitochondrial structure and contributes to stress-induced permeability transition in cardiac myocytes," Molecular and Cellular Biology, vol. 31, no. 6, pp. 1309-1328, 2011.

[136] S. Böckler and B. Westermann, "Mitochondrial ER contacts are crucial for mitophagy in yeast," Developmental Cell, vol. 28, no. 4, pp. 450-458, 2014.

[137] J. R. Friedman, L. L. Lackner, M. West, J. R. DiBenedetto, J. Nunnari, and G. K. Voeltz, "ER tubules mark sites of mitochondrial division," Science, vol. 334, no. 6054, pp. 358-362, 2011.
[138] A. A. Rowland and G. K. Voeltz, "Endoplasmic reticulum-mitochondria contacts: function of the junction," Nature Reviews Molecular Cell Biology, vol. 13, no. 10, pp. 607-615, 2012.

[139] J. Park, H. Choi, J.-S. Min et al., "Mitochondrial dynamics modulate the expression of pro-inflammatory mediators in microglial cells," Journal of Neurochemistry, vol. 127, no. 2, pp. 221-232, 2013.

[140] M. Hamasaki, N. Furuta, A. Matsuda et al., "Autophagosomes form at ER-mitochondria contact sites," Nature, vol. 495, no. 7441, pp. 389-393, 2013.

[141] L. Yang, P. Li, S. Fu, E. S. Calay, and G. S. Hotamisligil, "Defective hepatic autophagy in obesity promotes ER stress and causes insulin resistance," Cell Metabolism, vol. 11, no. 6, pp. 467-478, 2010.

[142] C. E. Nuñez, V. S. Rodrigues, F. S. Gomes et al., "Defective regulation of adipose tissue autophagy in obesity," International Journal of Obesity, vol. 37, no. 11, pp. 1473-1480, 2013.

[143] W. Quan, K. Y. Hur, Y. Lim et al., "Autophagy deficiency in beta cells leads to compromised unfolded protein response and progression from obesity to diabetes in mice," Diabetologia, vol. 55, no. 2, pp. 392-403, 2012.

[144] K. Liu, E. Zhao, G. Ilyas et al., "Impaired macrophage autophagy increases the immune response in obese mice by promoting proinflammatory macrophage polarization," Autophagy, vol. 11, no. 2, pp. 271-284, 2015.

[145] Z. He and H. U. Simon, "Autophagy protects from liver injury," Cell Death and Differentiation, vol. 20, no. 7, pp. 850-851, 2013.

[146] E. White, C. Karp, A. M. Strohecker, Y. Guo, and R. Mathew, "Role of autophagy in suppression of inflammation and cancer," Current Opinion in Cell Biology, vol. 22, no. 2, pp. 212-217, 2010.

[147] D. H. Perlmutter, "Autophagic disposal of the aggregation-prone protein that causes liver inflammation and carcinogenesis in $\alpha$ 1-antitrypsin deficiency," Cell Death and Differentiation, vol. 16, no. 1, pp. 39-45, 2009.

[148] E. F. Castillo, A. Dekonenko, J. Arko-Mensah et al., "Autophagy protects against active tuberculosis by suppressing bacterial burden and inflammation," Proceedings of the National Academy of Sciences of the United States of America, vol. 109, no. 46, pp. E3168-E3176, 2012.

[149] P. S. Manzanillo, J. S. Ayres, R. O. Watson et al., "The ubiquitin ligase parkin mediates resistance to intracellular pathogens," Nature, vol. 501, no. 7468, pp. 512-516, 2013.

[150] V. Deretic, T. Saitoh, and S. Akira, "Autophagy in infection, inflammation and immunity," Nature Reviews Immunology, vol. 13, no. 10, pp. 722-737, 2013.

[151] B. K. Davis, H. Wen, and J. P.-Y. Ting, "The Inflammasome NLRs in immunity, inflammation, and associated diseases," Annual Review of Immunology, vol. 29, pp. 707-735, 2011.

[152] V. A. K. Rathinam, S. K. Vanaja, and K. A. Fitzgerald, "Regulation of inflammasome signaling," Nature Immunology, vol. 13, no. 4, pp. 333-342, 2012.

[153] C.-S. Yang, J.-J. Kim, T. S. Kim et al., "Small heterodimer partner interacts with NLRP3 and negatively regulates activation of the NLRP3 inflammasome," Nature Communications, vol. 6, article no. $6115,2015$.

[154] J. A. Ehses, G. Lacraz, M.-H. Giroix et al., "IL-1 antagonism reduces hyperglycemia and tissue inflammation in the type 2 diabetic GK rat," Proceedings of the National Academy of Sciences of the United States of America, vol. 106, no. 33, pp. 13998-14003, 2009. 
[155] P. Menu, A. Mayor, R. Zhou et al., "ER stress activates the NLRP3 inflammasome via an UPR-independent pathway," Cell Death and Disease, vol. 3, no. 1, article e261, 2012.

[156] J. Masumoto, S. Taniguchi, K. Ayukawa et al., "ASC, a novel 22$\mathrm{kDa}$ protein, aggregates during apoptosis of human promyelocytic leukemia HL-60 cells," Journal of Biological Chemistry, vol. 274, no. 48, pp. 33835-33838, 1999.

[157] R. Stienstra, J. A. van Diepen, C. J. Tack et al., "Inflammasome is a central player in the induction of obesity and insulin resistance," Proceedings of the National Academy of Sciences of the United States of America, vol. 108, no. 37, pp. 15324-15329, 2011.

[158] Y.-H. Youm, A. Adijiang, B. Vandanmagsar, D. Burk, A. Ravussin, and V. D. Dixit, "Elimination of the NLRP3-ASC inflammasome protects against chronic obesity-induced pancreatic damage," Endocrinology, vol. 152, no. 11, pp. 4039-4045, 2011.

[159] D. Gao, M. Madi, C. Ding et al., "Interleukin-1 $\beta$ mediates macrophage-induced impairment of insulin signaling in human primary adipocytes," American Journal of Physiology-Endocrinology and Metabolism, vol. 307, no. 3, pp. E289-E304, 2014.

[160] B. Vandanmagsar, Y.-H. Youm, A. Ravussin et al., “The NLRP3 inflammasome instigates obesity-induced inflammation and insulin resistance," Nature Medicine, vol. 17, no. 2, pp. 179-189, 2011.

[161] S. M. Horner, H. M. Liu, H. S. Park, J. Briley, and M. Gale Jr., "Mitochondrial-associated endoplasmic reticulum membranes (MAM) form innate immune synapses and are targeted by hepatitis C virus," Proceedings of the National Academy of Sciences of the United States of America, vol. 108, no. 35, pp. 1459014595, 2011.

[162] R. B. Seth, L. Sun, C.-K. Ea, and Z. J. Chen, "Identification and characterization of MAVS, a mitochondrial antiviral signaling protein that activates NF- $\kappa$ B and IRF3," Cell, vol. 122, no. 5, pp. 669-682, 2005.

[163] M. Yoneyama, M. Kikuchi, T. Natsukawa et al., "The RNA helicase RIG-I has an essential function in double-stranded RNA-induced innate antiviral responses," Nature Immunology, vol. 5, no. 7, pp. 730-737, 2004.

[164] S. M. Horner, C. Wilkins, S. Badil, J. Iskarpatyoti, and M. Gale, "Proteomic analysis of mitochondrial-associated ER membranes (MAM) during RNA virus infection reveals dynamic changes in protein and organelle trafficking," PLOS ONE, vol. 10, no. 3, Article ID e0117963, 2015.

[165] T. Kawai, K. Takahashi, S. Sato et al., "IPS-1, an adaptor triggering RIG-I- and Mda5-mediated type I interferon induction," Nature Immunology, vol. 6, no. 10, pp. 981-988, 2005.

[166] N. Subramanian, K. Natarajan, M. R. Clatworthy, Z. Wang, and R. N. Germain, "The adaptor MAVS promotes NLRP3 mitochondrial localization and inflammasome activation," Cell, vol. 153, no. 2, pp. 348-361, 2013.

[167] L. Alvarez-Erviti, Y. Couch, J. Richardson, J. M. Cooper, and M. J. A. Wood, "Alpha-synuclein release by neurons activates the inflammatory response in a microglial cell line," Neuroscience Research, vol. 69, no. 4, pp. 337-342, 2011.

[168] M. Mogi, M. Harada, T. Kondo et al., "Interleukin-1 $\beta$, interleukin-6, epidermal growth factor and transforming growth factor- $\alpha$ are elevated in the brain from parkinsonian patients," Neuroscience Letters, vol. 180, no. 2, pp. 147-150, 1994.

[169] M. Mogi, M. Harada, P. Riederer, H. Narabayashi, K. Fujita, and T. Nagatsu, "Tumor necrosis factor- $\alpha$ (TNF- $\alpha$ ) increases both in the brain and in the cerebrospinal fluid from parkinsonian patients," Neuroscience Letters, vol. 165, no. 1-2, pp. 208-210, 1994.

[170] K. Imamura, N. Hishikawa, M. Sawada, T. Nagatsu, M. Yoshida, and Y. Hashizume, "Distribution of major histocompatibility complex class II-positive microglia and cytokine profile of Parkinson's disease brains," Acta Neuropathologica, vol. 106, no. 6, pp. 518-526, 2003.

[171] M. Reale, C. Iarlori, A. Thomas et al., "Peripheral cytokines profile in Parkinson's disease," Brain, Behavior, and Immunity, vol. 23, no. 1, pp. 55-63, 2009.

[172] M. Mogi, A. Togari, M. Ogawa et al., "Effects of repeated systemic administration of 1-methyl-4- phenyl1,2,3,6-tetrahydropyridine (MPTP) to mice on interleukin- $1 \beta$ and nerve growth factor in the striatum," Neuroscience Letters, vol. 250, no. 1, pp. 25-28, 1998.

[173] H.-M. Gao, J. Jiang, B. Wilson, W. Zhang, J.-S. Hong, and B. Liu, "Microglial activation-mediated delayed and progressive degeneration of rat nigral dopaminergic neurons: relevance to Parkinson's disease," Journal of Neurochemistry, vol. 81, no. 6, pp. 1285-1297, 2002.

[174] E. Rousselet, J. Callebert, K. Parain et al., "Role of TNF$\alpha$ receptors in mice intoxicated with the parkinsonian toxin MPTP," Experimental Neurology, vol. 177, no. 1, pp. 183-192, 2002.

[175] C. Klein and A. Westenberger, "Genetics of Parkinson's disease," Cold Spring Harbor Perspectives in Medicine, vol. 2, no. 1, Article ID a008888, 2012.

[176] D. L. Fortin, M. D. Troyer, K. Nakamura, S.-I. Kubo, M. D. Anthony, and R. H. Edwards, "Lipid rafts mediate the synaptic localization of $\alpha$-synuclein," Journal of Neuroscience, vol. 24, no. 30, pp. 6715-6723, 2004.

[177] N. B. Cole, D. DiEuliis, P. Leo, D. C. Mitchell, and R. L. Nussbaum, "Mitochondrial translocation of $\alpha$-synuclein is promoted by intracellular acidification," Experimental Cell Research, vol. 314, no. 10, pp. 2076-2089, 2008.

[178] W.-W. Li, R. Yang, J.-C. Guo et al., "Localization of $\alpha$-synuclein to mitochondria within midbrain of mice," NeuroReport, vol.18, no. 15, pp. 1543-1546, 2007.

[179] R. Sherrington, E. I. Rogaev, Y. Liang et al., "Cloning of a gene bearing missense mutations in early-onset familial Alzheimer's disease," Nature, vol. 375, no. 6534, pp. 754-760, 1995.

[180] Q. Lu, K. Ding, M. P. Frosch et al., "Alzheimer's disease-linked presenilin mutation (PS1M146L) induces filamin expression and $\gamma$-secretase independent redistribution," Journal of Alzheimer's Disease, vol. 22, no. 1, pp. 235-245, 2010.

[181] S. Weggen and D. Beher, "Molecular consequences of amyloid precursor protein and presenilin mutations causing autosomaldominant Alzheimer's disease," Alzheimer's Research and Therapy, vol. 4, no. 2, article 9, 2012.

[182] B. De Strooper, "Loss-of-function presenilin mutations in Alzheimer disease. Talking Point on the role of presenilin mutations in Alzheimer disease," EMBO Reports, vol. 8, no. 2, pp. 141-146, 2007.

[183] E. Area-Gomez, A. J. C. De Groof, I. Boldogh et al., "Presenilins are enriched in endoplasmic reticulum membranes associated with mitochondria," American Journal of Pathology, vol. 175, no. 5, pp. 1810-1816, 2009.

[184] A. Parachikova, M. G. Agadjanyan, D. H. Cribbs et al., "Inflammatory changes parallel the early stages of Alzheimer disease," Neurobiology of Aging, vol. 28, no. 12, pp. 1821-1833, 2007. 
[185] J. Lee, S. L. Chan, and M. P. Mattson, "Adverse effect of a presenilin-1 mutation in microglia results in enhanced nitric oxide and inflammatory cytokine responses to immune challenge in the brain," NeuroMolecular Medicine, vol. 2, no. 1, pp. 29-45, 2002.

[186] J. Deng, P. D. Lu, Y. Zhang et al., "Translational repression mediates activation of nuclear factor kappa B by phosphorylated translation initiation factor 2," Molecular and Cellular Biology, vol. 24, no. 23, pp. 10161-10168, 2004.

[187] P. E. Kolattukudy and J. Niu, "Inflammation, endoplasmic reticulum stress, autophagy, and the monocyte chemoattractant protein-1/CCR2 pathway," Circulation Research, vol. 110, no. 1, pp. 174-189, 2012.

[188] T. Verfaillie, N. Rubio, A. D. Garg et al., "PERK is required at the ER-mitochondrial contact sites to convey apoptosis after ROSbased ER stress," Cell Death \& Differentiation, vol. 19, no. 11, pp. 1880-1891, 2012.

[189] P. Pinton, C. Giorgi, and P. P. Pandolf, "The role of PML in the control of apoptotic cell fate: a new key player at ER-mitochondria sites," Cell Death and Differentiation, vol. 18, no. 9, pp. 1450-1456, 2011.

[190] N. D. Lakin and S. P. Jackson, "Regulation of p53 in response to DNA damage," Oncogene, vol. 18, no. 53, pp. 7644-7655, 1999.

[191] H. C. Reinhardt and B. Schumacher, “The p53 network: cellular and systemic DNA damage responses in aging and cancer," Trends in Genetics, vol. 28, no. 3, pp. 128-136, 2012.

[192] Y. Haupt, S. Rowan, E. Shaulian, K. H. Vousden, and M. Oren, "Induction of apoptosis in HeLa cells by trans-activation-deficient p53," Genes and Development, vol. 9, no. 17, pp. 2170-2183, 1995.

[193] A. Ventura, M. Maccarana, V. A. Raker, and P. G. Pelicci, "A cryptic targeting signal induces isoform-specific localization of p46Shc to mitochondria," Journal of Biological Chemistry, vol. 279, no. 3, pp. 2299-2306, 2004.

[194] M. Giorgio, E. Migliaccio, F. Orsini et al., "Electron transfer between cytochrome $\mathrm{c}$ and p66Shc generates reactive oxygen species that trigger mitochondrial apoptosis," Cell, vol. 122, no. 2, pp. 221-233, 2005.

[195] M. Gertz, F. Fischer, D. Wolters, and C. Steegborn, "Activation of the lifespan regulator p66Shc through reversible disulfide bond formation," Proceedings of the National Academy of Sciences of the United States of America, vol. 105, no. 15, pp. 5705-5709, 2008.

[196] C. S. Calfee and M. A. Matthay, "Clinical immunology: culprits with evolutionary ties," Nature, vol. 464, no. 7285, pp. 41-42, 2010.

[197] T. H. Mogensen, "Pathogen recognition and inflammatory signaling in innate immune defenses," Clinical Microbiology Reviews, vol. 22, no. 2, pp. 240-273, 2009.

[198] G. Y. Chen and G. Nuñez, "Sterile inflammation: sensing and reacting to damage," Nature Reviews Immunology, vol. 10, no. 12, pp. 826-837, 2010.

[199] H. Guo, J. B. Callaway, and J. P.-Y. Ting, "Inflammasomes: mechanism of action, role in disease, and therapeutics," Nature Medicine, vol. 21, no. 7, pp. 677-687, 2015.

[200] Y. Zheng, S. E. Gardner, and M. C. H. Clarke, "Cell death, damage-associated molecular patterns, and sterile inflammation in cardiovascular disease," Arteriosclerosis, Thrombosis, and Vascular Biology, vol. 31, no. 12, pp. 2781-2786, 2011.
[201] D. V. Krysko, P. Agostinis, O. Krysko et al., "Emerging role of damage-associated molecular patterns derived from mitochondria in inflammation," Trends in Immunology, vol. 32, no. 4, pp. 157-164, 2011.

[202] D. N. Bronner, B. H. Abuaita, X. Chen et al., "Endoplasmic Reticulum Stress Activates the Inflammasome via NLRP3- and Caspase-2-Driven Mitochondrial Damage," Immunity, vol. 43, no. 3, article 3151, pp. 451-462, 2015.

[203] C. M. Oslowski, T. Hara, B. O'Sullivan-Murphy et al., "Thioredoxin-interacting protein mediates ER stress-induced $\beta$ cell death through initiation of the inflammasome," Cell Metabolism, vol. 16, no. 2, pp. 265-273, 2012.

[204] A. G. Lerner, J.-P. Upton, P. V. K. Praveen et al., "IRE1 $\alpha$ induces thioredoxin-interacting protein to activate the NLRP3 inflammasome and promote programmed cell death under irremediable ER stress," Cell Metabolism, vol. 16, no. 2, pp. 250-264, 2012.

[205] T. Mori, T. Hayashi, E. Hayashi, and T.-P. Su, "Sigma-1 receptor chaperone at the ER-mitochondrion interface mediates the mitochondrion-ER-nucleus signaling for cellular survival," PLoS ONE, vol. 8, no. 10, Article ID e76941, 2013.

[206] E. Tubbs, P. Theurey, G. Vial et al., "Mitochondria-associated endoplasmic reticulum membrane (MAM) integrity is required for insulin signaling and is implicated in hepatic insulin resistance," Diabetes, vol. 63, no. 10, pp. 3279-3294, 2014.

[207] K. Nakahira, J. A. Haspel, V. A. K. Rathinam et al., "Autophagy proteins regulate innate immune responses by inhibiting the release of mitochondrial DNA mediated by the NALP3 inflammasome," Nature Immunology, vol. 12, no. 3, pp. 222-230, 2011.

[208] J. Priber, F. Fonai, P. B. Jakus et al., "Cyclophilin D disruption attenuates lipopolysaccharide-induced inflammatory response in primary mouse macrophages," Biochemistry and Cell Biology, vol. 93, no. 3, pp. 241-250, 2015.

[209] G. S. Hotamisligil, "Inflammation and metabolic disorders," Nature, vol. 444, no. 7121, pp. 860-867, 2006.

[210] M. Bäck and G. K. Hansson, "Anti-inflammatory therapies for atherosclerosis," Nature Reviews Cardiology, vol. 12, no. 4, pp. 199-211, 2015.

[211] F. L. Heppner, R. M. Ransohoff, and B. Becher, "Immune attack: the role of inflammation in Alzheimer disease," Nature Reviews Neuroscience, vol. 16, no. 6, pp. 358-372, 2015.

[212] J. E. Vance, "MAM (mitochondria-associated membranes) in mammalian cells: lipids and beyond," Biochimica et Biophysica Acta-Molecular and Cell Biology of Lipids, vol. 1841, no. 4, pp. 595-609, 2014. 


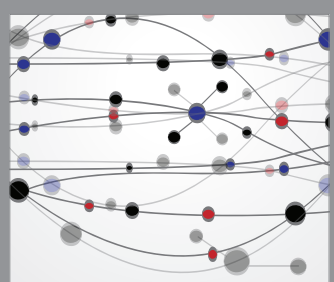

The Scientific World Journal
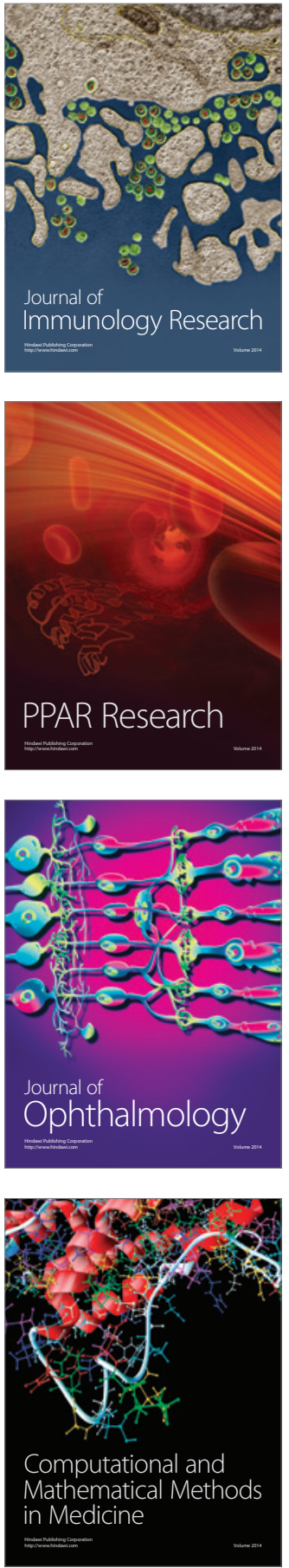

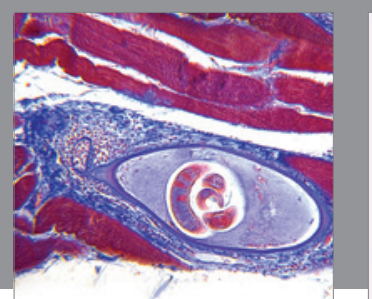

Gastroenterology Research and Practice

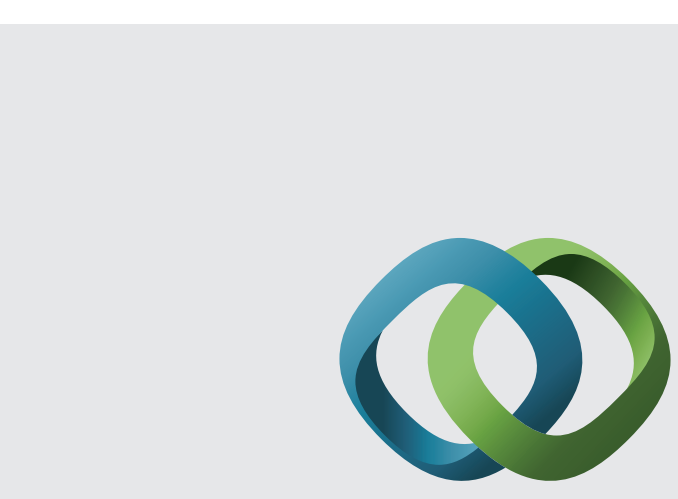

\section{Hindawi}

Submit your manuscripts at

http://www.hindawi.com
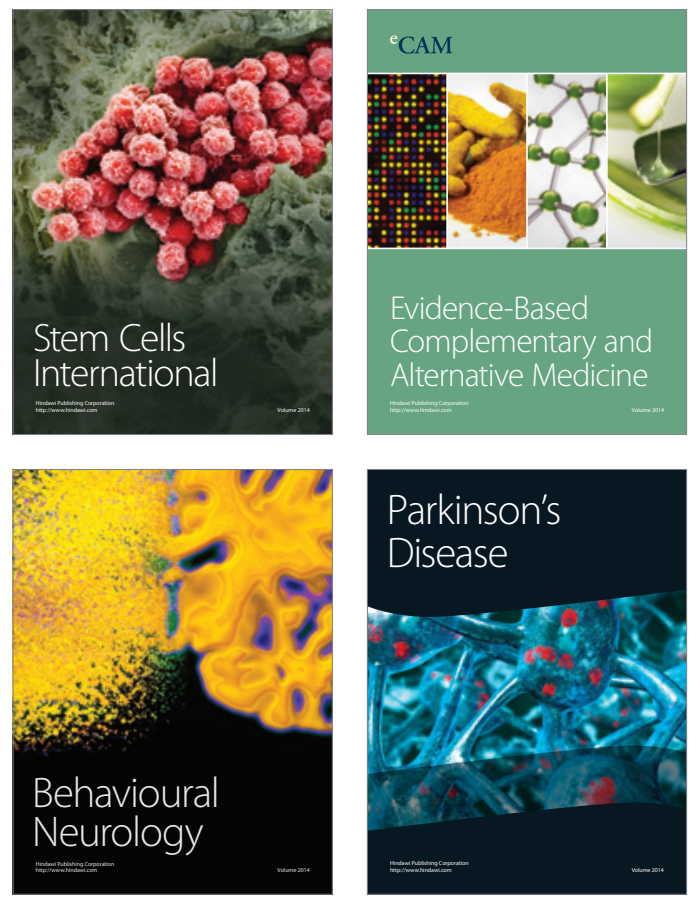
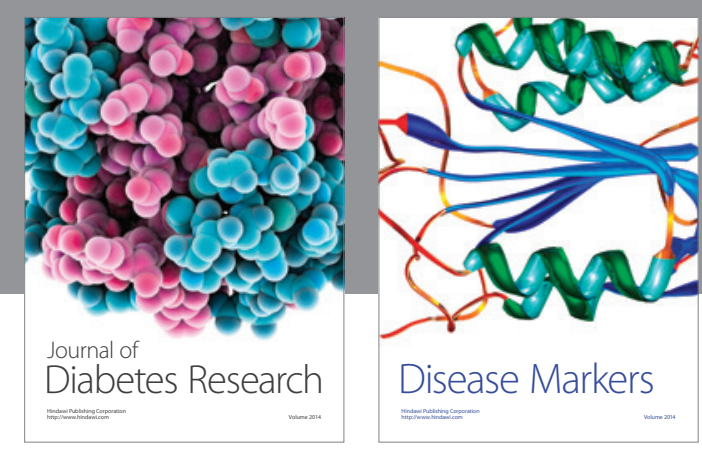

Disease Markers
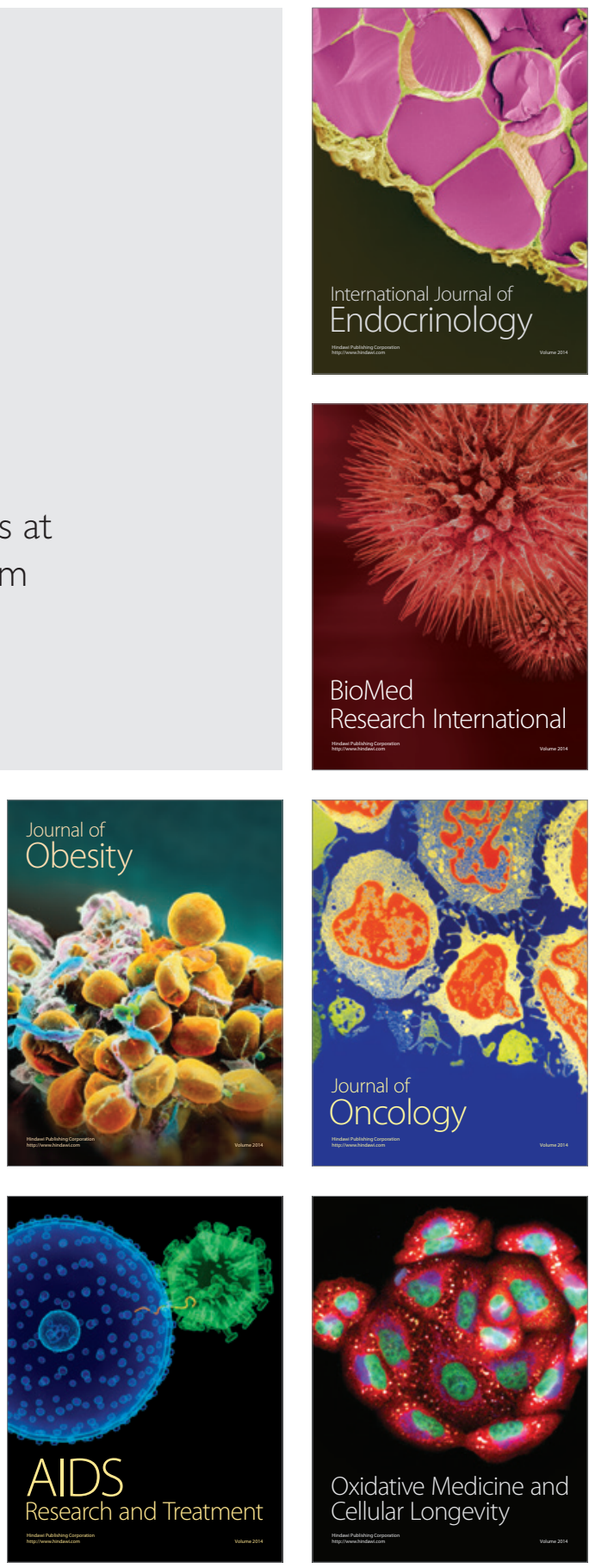